\title{
The Aurora kinase A inhibitor TC-A2317 disrupts mitotic progression and inhibits cancer cell proliferation
}

\author{
Yoo Hong Min ${ }^{1}$, Wootae Kim ${ }^{1}$, Ja-Eun Kim ${ }^{1,2}$ \\ ${ }^{1}$ Department of Biomedical Science, Graduate School, Kyung Hee University, Seoul 130-701, Republic of Korea \\ ${ }^{2}$ Department of Pharmacology, School of Medicine, Kyung Hee University, Seoul 130-701, Republic of Korea \\ Correspondence to: Ja-Eun Kim, email: jekim@khu.ac.kr \\ Keywords: Aurora kinase A, TC-A2317, mitosis, spindle assembly checkpoint
}

Abbreviations: Spindle assembly checkpoint, SAC.

Received: June 06, $2016 \quad$ Accepted: September 16, 2016

Published: October 04, 2016

\section{ABSTRACT}

Mitotic progression is crucial for the maintenance of chromosomal stability. A proper progression is ensured by the activities of multiple kinases. One of these enzymes, the serine/threonine kinase Aurora A, is required for proper mitosis through the regulation of centrosome and spindle assembly. In this study, we functionally characterized a newly developed Aurora kinase A inhibitor, TC-A2317. In human lung cancer cells, TC-A2317 slowed proliferation by causing aberrant formation of centrosome and microtubule spindles and prolonging the duration of mitosis. Abnormal mitotic progression led to accumulation of cells containing micronuclei or multinuclei. Furthermore, TC-A2317-treated cells underwent apoptosis, autophagy or senescence depending on cell type. In addition, TC-A2317 inactivated the spindle assembly checkpoint triggered by paclitaxel, thereby exacerbating mitotic catastrophe. Consistent with this, the expression level of Aurora A in tumors was inversely correlated with survival in lung cancer patients. Collectively, these data suggest that inhibition of Aurora kinase A using TC-A2317 is a promising target for anti-cancer therapeutics.

\section{INTRODUCTION}

Mitosis is a critical step in the segregation of chromosomes to daughter cells. Proper chromosome segregation is ensured by the spindle assembly checkpoint (SAC), also known as the mitotic checkpoint, which is regulated by a diverse set of kinases [1]. Among the factors responsible for the proper progression of mitosis are the Aurora family of serine/threonine kinases [2]. The first Aurora kinase, discovered in a Drosophila melanogaster mutant with monopolar spindles due to defect in centrosome seperation, is functionally related to Increase-in-ploidy 1 (IPL1) in Saccharomyces cerevisiae, Aurora-related kinase 1 (ARK1) in Schizosaccharomyces pombe, and Aurora/ IPL1-related kinase (AIK) in mammals [3]. The three mammalian Aurora paralogs are Aurora A, Aurora B and Aurora C. Aurora C primarily regulates the meiotic cell cycle, but its function remains incompletely understood [4]. Aurora B regulates chromosome condensation, chromosome biorientiation, SAC, regulation of sister chromatid cohesion, spindle disassembly, and cytokinesis [5].
Aurora A is also known as serine/threonine protein kinase 15 (STK15), serine/threonine protein kinase 6 (STK6), breast tumor-amplified kinase (BTAK), Aurorarelated kinase 1 (ARK-1), Aurora/IPL1-related kinase (AIK), and Aurora 2. It controls mitotic regulatory functions in centrosome maturation, centrosome separation, mitotic entry, chromosome alignment, bipolar spindle formation, and cytokinesis; consequently, tight regulation of Aurora kinase $\mathrm{A}$ is required for proper mitotic progression [6, 7]. Depletion of Aurora A induces monopolar spindle formation, prometaphase arrest, aneuploidy, apoptosis, or senescence [8]. Overexpression of Aurora A induces centrosome amplification, multipolar spindle formation, aneuploidy, and defects in the SAC $[9,10]$. Recently, Aurora A was proposed to play non-mitotic regulatory functions in cell migration, cilium disassembly, calcium signaling, cell polarity, DNA repair, DNA replication, pluripotency, p53 activity, and NF- $\mathrm{NB}$ signaling $[6,8]$.

The various functions of Aurora A are governed by localization, expression, and activity. Aurora A is localized to the centrosome from late $S$ to early G1 
phase, and is also localized in the spindle pole and spindle microtubules throughout mitosis, consistent with its roles in the centrosome and spindle [11]. Expression of Aurora A protein is low in G1/S phase, but peaks at G2 and early mitosis [10]. Over the course of the cell cycle, its expression is regulated at the transcriptional level; specifically, it is positively regulated by E4TF1 and repressed by tandem elements, the CDE (cell cycledependent element) and CHR (cell cycle gene homology region) sequences [12]. Upregulated Aurora A protein is degraded in late mitosis following recognition of its N-terminal A-box and C-terminal D-box by the Cdh1dependent anaphase-promoting complex/cyclosome (APC/C) although the N-terminal KEN-box is not required at this stage [6]. Degradation is completed in G1 phase. In addition to the $\mathrm{APC} / \mathrm{C}$, several other factors including Chfr, Fbxw7, AURKAIP1, Az1, GSK-3 $\beta$, and PP2A regulate Aurora A protein expression [6]. The activity of Aurora kinase A is increased by autophosphorylation of T288 in the activating T-loop. This autophosphorylation is activated by cofactors such as TPX2, Ajuba, NEDD9, Bora, calmodulin, and PAK1 at centrosome; T288 is dephosphorylated by PP1 [6].

The AURKA gene on chromosome $20 \mathrm{q} 13$ is amplified, or Aurora A is overexpressed, in a wide range of cancers including bladder, breast, colorectal, gastric, head and neck, liver, lung, neuronal, ovarian, and prostate cancer, leukemia and lymphoma [8]. This amplification/ overexpression is associated with unfavorable prognosis and low survival. Aurora A overexpression induces cell transformation [13] and mammary tumor development [14]. Aurora B is also overexpressed in many types of cancers, but its role in tumorigenesis has not been clearly defined [15]. Therefore, specific inhibition of Aurora kinase A may be useful as a cancer treatment. Several specific Aurora kinase A inhibitors, including ENMD2076, MK-5108 (VX-689), MLN-8054, and MLN-8237 (alisertib), are undergoing clinical trials [8, 16, 17]. Although TC-A2317 was developed as a specific Aurora kinase A inhibitor [18], its anti-tumor effect has been investigated only in glioblastoma [19], and its mechanism has not been elucidated. In this study, we found that TCA2317 also inhibits lung cancer cell proliferation by inducing mitotic catastrophe, suggesting that it might be effective against lung cancer.

\section{RESULTS}

\section{TC-A2317 decreases cell survival}

We aimed to determine the short- and long-term effect of pharmacological inhibition of Aurora kinase A activity on the survival of lung cancer cells. For this purpose, we treated A549, A427 and NCI-H1299 cells with TC-A2317, a specific Aurora kinase A inhibitor. Treatment of cells with TC-A2317 for $24 \mathrm{hr}$ significantly decreased cell viability in a dose-dependent manner (Figure 1A). In addition, A549 cells treated with TCA2317 showed dramatically reduced colony-forming activity, indicating that the drug exerted a long-term effect (Figure 1B). Together, these results show that TC-A2317 decreases the survival of lung cancer cells.

\section{TC-A2317 causes cells to undergo abnormal cell division}

We next investigated the causes of reduced cell survival following TC-A2317 treatment. Analysis of cell cycle distribution revealed that TC-A2317 treatment led to significant accumulation of cells with 4N DNA content in A549, A427 and NCI-H1299 cells (Figure 2A and Supplementary Figure S1A). To determine whether these cells represented a $\mathrm{G} 2 / \mathrm{M}$-arrested population, we monitored the level of $\mathrm{H} 3-\mathrm{pS} 10$, which is normally upregulated at late G2 and M phase. TC-A2317-treated cells exhibited a dramatic reduction in $\mathrm{H} 3-\mathrm{pS} 10$ level (Figure 2B and Supplementary Figure S1A), suggesting that the accumulation of cells with 4N DNA was not due to G2/M arrest. In addition, cells with $>4 \mathrm{~N}$ DNA content were significantly accumulated, indicating that TC-A2317 induces formation of polyploidy (Figure 2A and Supplementary Figure S1A). In particular, because NCI-H1299 cells are rapidly dividing, they showed even 16N DNA content (Supplementary Figure S1A). It demonstrates that all three cells are endoreduplicated. Simultaneously, sub-G1 population increased in TCA-2317-treated cells in a time-dependent manner, implying that TC-A2317 induces cell death (Figure 2C and Supplementary Figure S1A). The most well-known Aurora A inhibitor, alisertib also results in the similar change of cell cycle in A549 cells (Supplementary Figure 1B). However, vehicle does not affect cell cycle phase, H3-pS10 level, and sub-G1 population (Supplementary Figure S1C). Nuclear staining also revealed that TC-A2317-treated A549 cells exhibited abnormal nucleation (Figure 2D). The proportions of cells exhibiting micronucleation and multinucleation increased significantly over time. Alisertib-treated cells also contained micronuclei and multinuclei (Supplementary Figure S2A). Together, these data demonstrate that Aurora A inhibition induces abnormal nuclear cell division and the formation of aneuploidy.

\section{TC-A2317 causes aberrant mitotic progression}

Aneuploidy, including micronucleation and multinucleation, can occur as a consequence of abnormal mitotic division. To determine whether asymmetrical centrosomes or abnormal mitotic spindles were responsible for the aneuploidy described above, we stained cells for pericentrin, a component of the pericentriolar material (PCM), and $\alpha$-tubulin, respectively. A549 cells 
treated with DMSO normally displayed either one or two centrosome(s). A majority of interphase cells treated with TC-A2317 contained one centrosome, but the very small number of interphase cells contained two centrosomes, which are very adjacent (Figure 3A). However, alisertibtreated cells contained multiple centrosomes, which are closely located, as well as one centrosome (Supplementary Figure S2A). These observations suggest that Aurora A inhibition induced asymmetrical mitotic division. Because TC-A2317 reduced a proportion of mitotic cells and might induce cell cycle arrest in interphase after treatment for 24-72 hr (Figure 2B), we could not observe centrosomes and mitotic spindles during mitosis. Therefore, those were examined following a brief incubation with TCA2317 for $30 \mathrm{~min}$ or $1 \mathrm{hr}$. First, while two centrosomes were separated toward opposing sides in control cells, they were not fully separated in TC-A2317-treated cells at prometaphase (Figure 3B and 6A, and Supplementary Figure S5A). It indicates that Aurora A inhibition leads to a failure in centrosome separation. Second, we determined the stability of mitotic spindles by performing microtubule depolymerization assays. The rate of microtubule depolymerization was higher in TC-A2317-treated cells than in controls cells (Figure 3C), indicating that TCA2317 treatment destabilizes mitotic spindles. Overall, these results suggest that abnormal centrosomes and unstable mitotic spindles exacerbate mitotic catastrophe. Consistent with this, live-cell imaging revealed that TCA2317 treatment resulted in formation of multi- and micro-nucleated cells and cell death, whereas control cells underwent division into two daughter cells (Figure 3D). In addition, the duration of mitosis was extended in TCA2317-treated cells relative to control cells (Figure 3E); mitotic delay can result in cell death (Figure 1). Together,

A

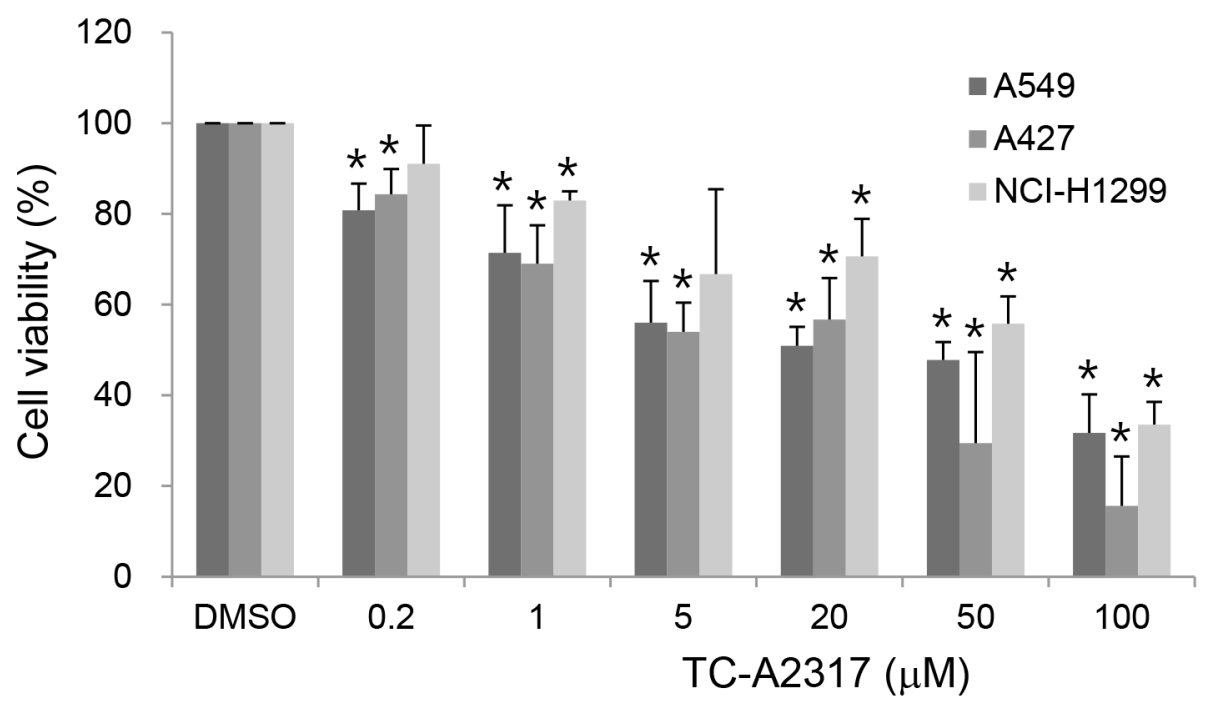

B
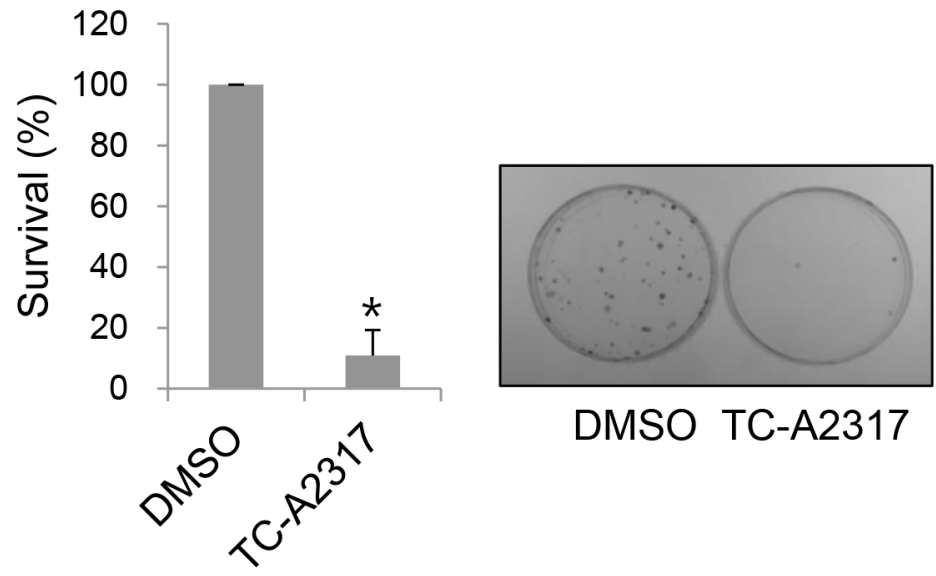

Figure 1: TC-A2317 inhibits cell proliferation. A. A549, A427 and NCI-H1299 cells were treated with various concentrations of TC-A2317 for $24 \mathrm{hr}$. Cell viability was determined using the MTT assay. B. A549 cells were treated with $1 \mu \mathrm{M}$ TC-A2317 for $24 \mathrm{hr}$. After removal of TC-A2317, the cells were seeded for colony growth. Colonies were counted after 14 days. All values from three independent experiments are represented as means \pm standard deviation $(\mathrm{n}=3)$. Asterisks $(*)$ represent statistically significant differences $(P<0.05$, Student's $t$-test). 

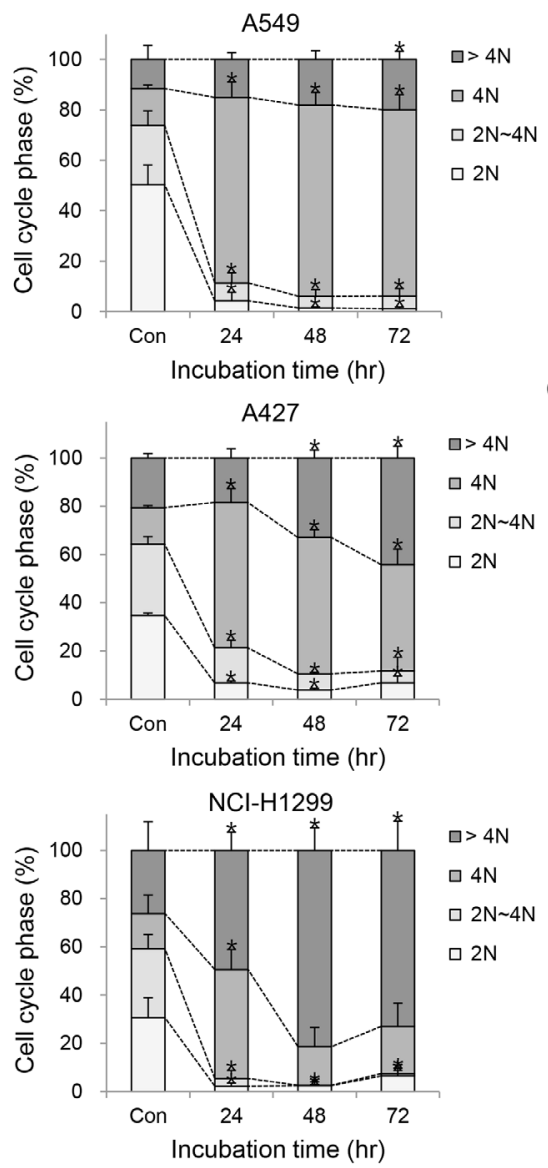

D

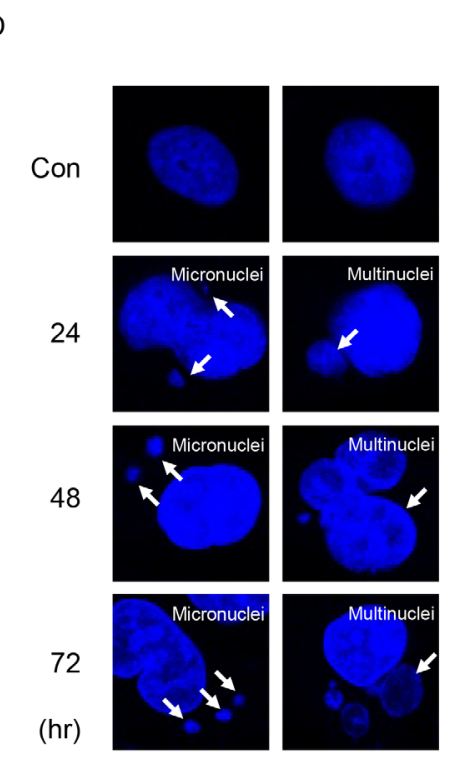

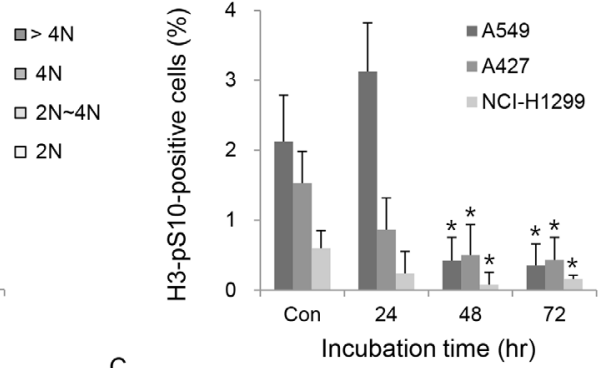

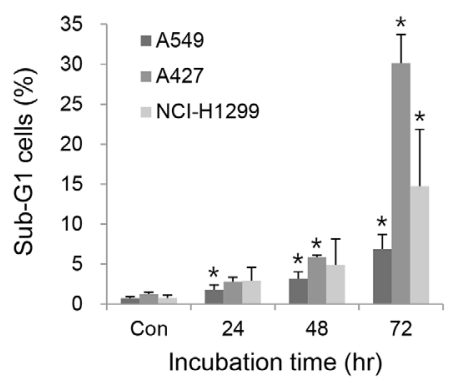

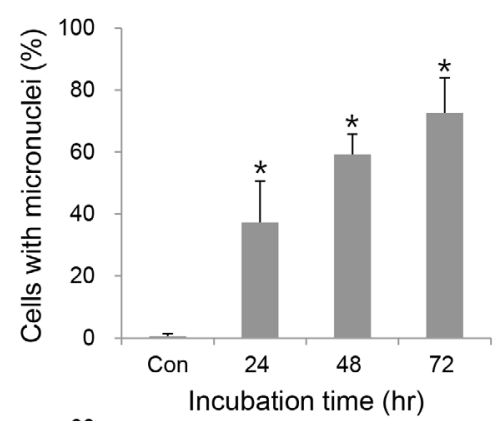

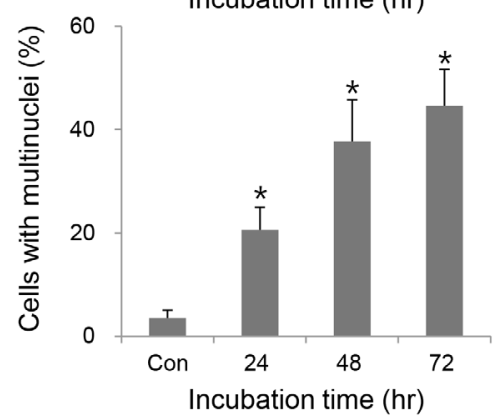

Figure 2: TC-A2317 induces the abnormal progression of cell cycle. A-C. A549, A427 and NCI-H1299 cells were treated with $1 \mu \mathrm{M}$ TC-A2317 for the indicated times. Cell cycle distribution (A), mitotic fraction (B), and sub-G1 population (C) were analyzed by flow cytometry by staining cells with PI and anti-H3-pS10. D. A549 cells were treated with $1 \mu \mathrm{M}$ TC-A2317 for the indicated times. Nuclei were visualized by staining with Hoechst. Cells with micronuclei and multinuclei were counted. Con (Control) means cells treated with vehicle (DMSO) for $72 \mathrm{hr}$. All values from three independent experiments are represented as means \pm standard deviation $(\mathrm{n}=3)$. Asterisks $(*)$ represent statistically significant differences $(P<0.05$, Student's $t$-test). 
A

Chromosome $\alpha$-Tubulin Pericentrin Merge

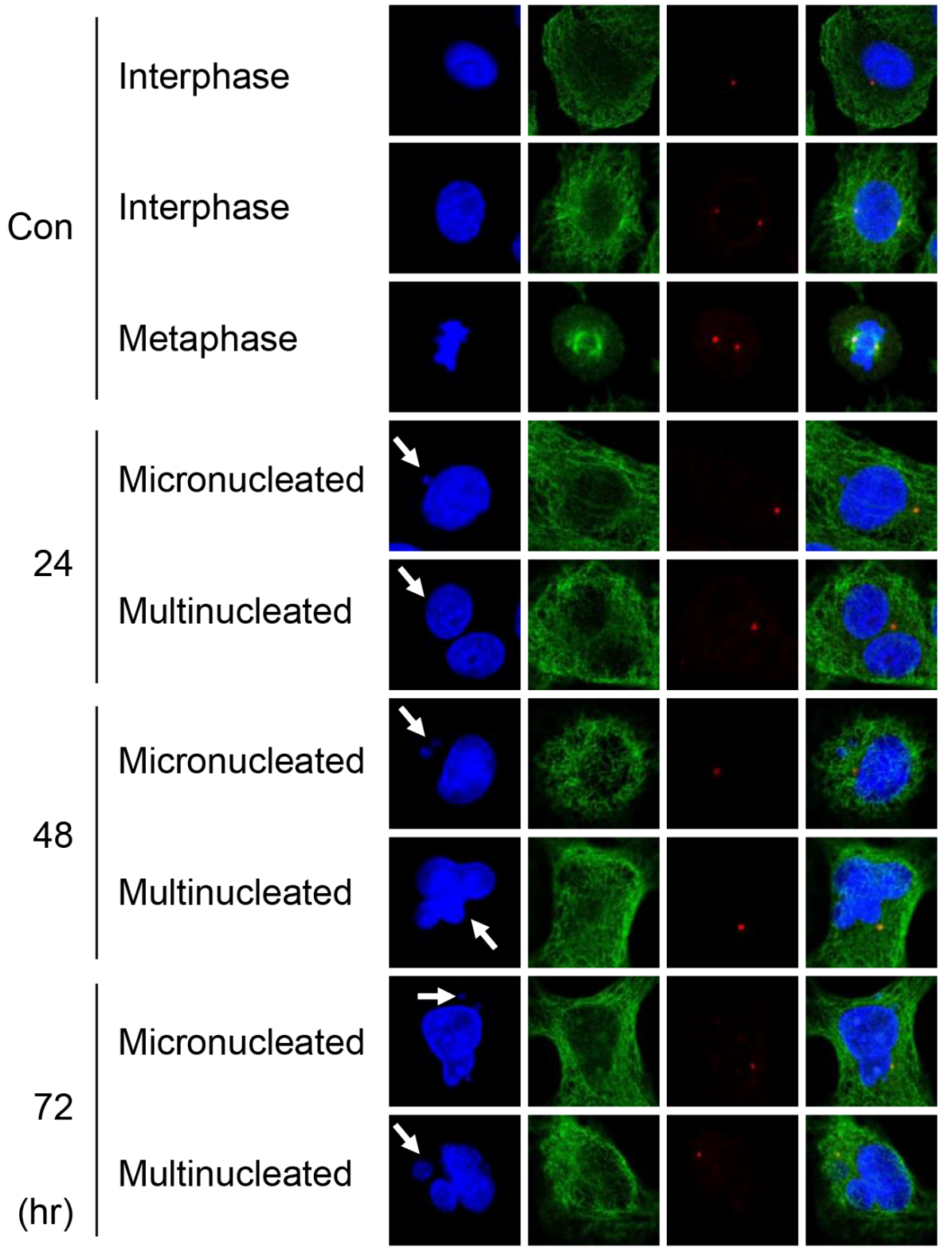

B

Chromosome $\alpha$-Tubulin Pericentrin Merge

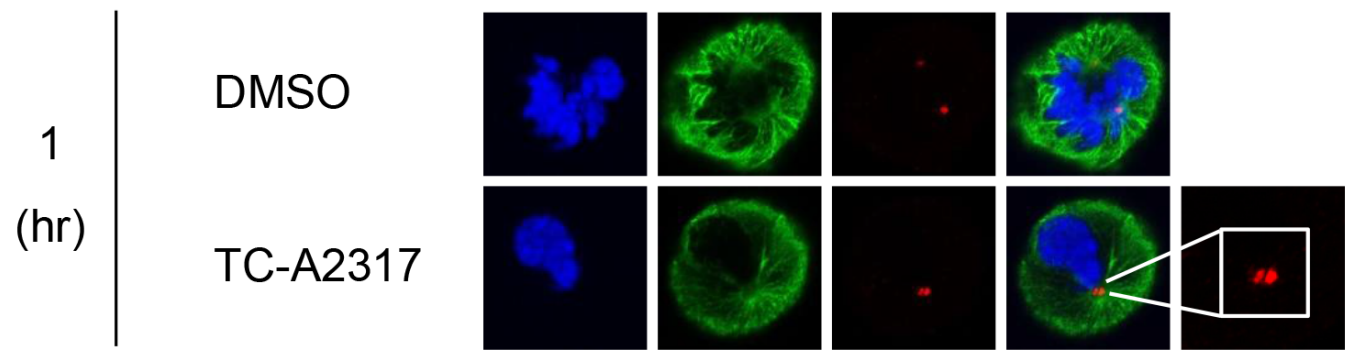

Figure 3: TC-A2317 results in abnormal centrosome formation, microtubule destabilization and prolonged mitosis. A-B. A549 cells were treated with $1 \mu \mathrm{M}$ TC-A2317 for the indicated times, and then subjected to immunofluorescence staining with antibodies against $\alpha$-tubulin and pericentrin. Con (Control) means cells treated with vehicle (DMSO) for $24 \mathrm{hr}$. (Continued) 


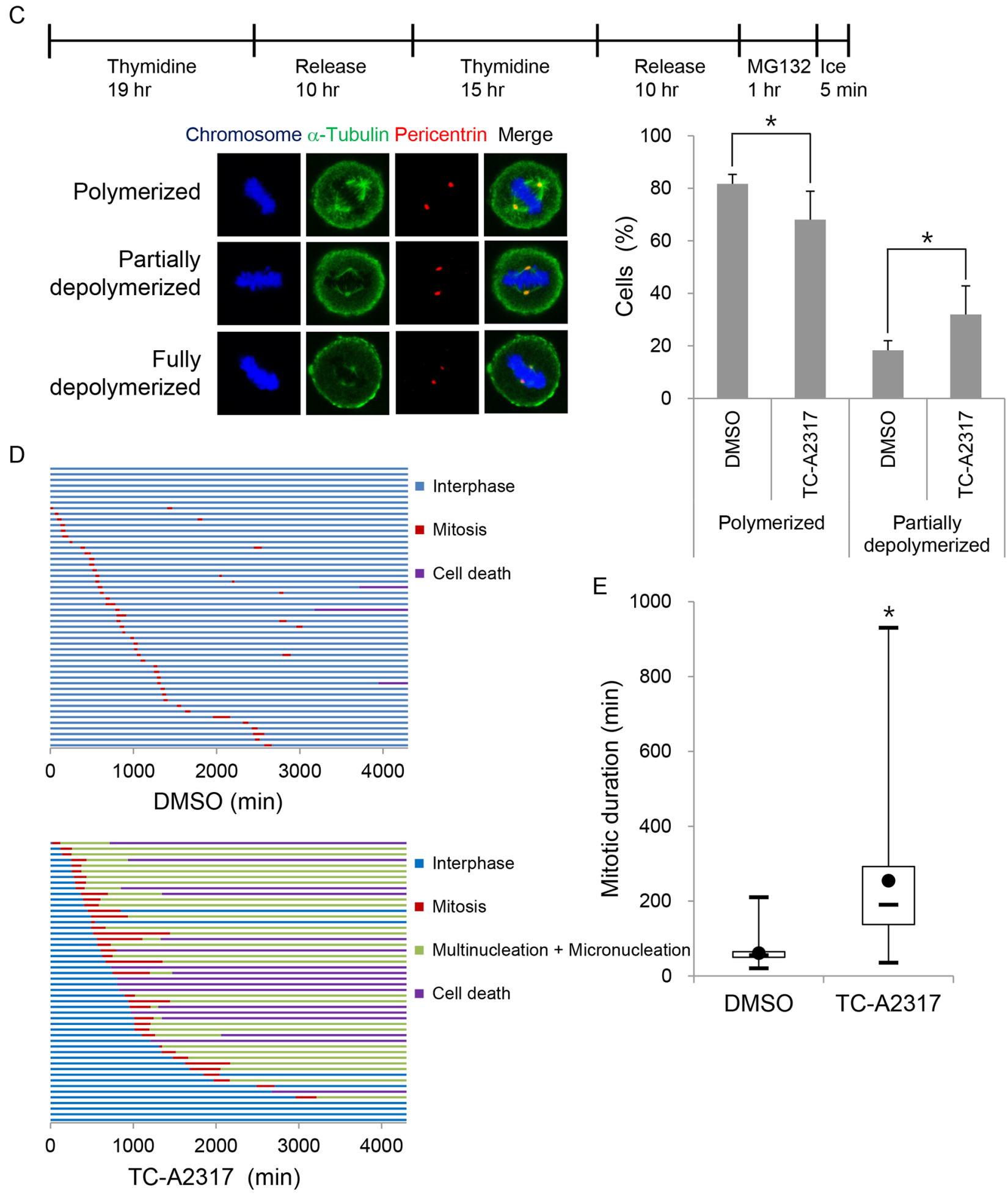

Figure 3: (Continued)TC-A2317 results in abnormal centrosome formation, microtubule destabilization and prolonged mitosis. C. A549 cells were enriched in mitosis after release from a double-thymidine block, treated with $20 \mu \mathrm{M} \mathrm{MG132} \mathrm{for} 1 \mathrm{hr}$, and then treated with $1 \mu \mathrm{M}$ TC-A2317 for 5 min on ice. Depolymerization of mitotic spindles was determined by visualizing mitotic spindles with $\alpha$-tubulin antibody. The number of metaphase cells with depolymerized mitotic spindles was counted. All values from three independent experiments are represented as means \pm standard deviation $(\mathrm{n}=3)$. D-E. H2B-RFP-transduced A549 cells were treated with $0.1 \%$ DMSO or $1 \mu \mathrm{M}$ TC-A2317 for $72 \mathrm{hr}$. Cells were monitored by time-lapse fluorescence microscopy. (D) Cells undergoing interphase, mitosis, multi- and micro-nucleation, and cell death were counted $(\mathrm{n}=50)$. (E) Duration of mitosis was represented in box-and-whisker plot. Box, interquartile range; whisker, min and max; black circle, average; bar, median. Asterisks $\left({ }^{*}\right)$ represent statistically significant differences $(P<0.05$, Student's $t$-test $)$. 
these data demonstrate that TC-A2317 treatment perturbs mitotic progression and contributes to the accumulation of chromosomal abnormalities.

\section{TC-A2317-treated cells undergo apoptosis, autophagy, or senescence}

Next, we investigated the consequences of abnormal mitotic progression. First, we sought to explain the cell death observed in Figure 3D. In A549 cells, cleavage of PARP-1 was very slightly induced $24 \mathrm{hr}$ after TC-A2317 treatment, but reduced at later stages of TC-A2317 treatment (i.e., at 48 and $72 \mathrm{hr}$; Figure 4A). It indicated that a minority of A549 cells had undergone apoptosis (Figure 4A). Thus, a subset of A549 cells overcame apoptosis and followed another fate. By contrast, cleavage of PARP-1 significantly increased in a timedependent manner when TC-A2317 was treated in A427 and NCI-H1299 cells, indicating that they underwent apoptosis (Figure 4A). It implicates that lung cancer cells with different genetic background underwent different types of cell death. Another possible outcome was autophagy, reflected by reduced levels of p62/SQSTM1, an ubiquitin-binding scaffold protein, and elevated levels of LC3-II, a marker of autophagosome formation. TCA2317 treatment enhanced autophagy-related changes in A549, A427 and NCI-H1299 cells (Figure 4B). Autophagy induced by TC-A2317 treatment could be causally related to low cell survival (Figure 1). In addition, the scarcity of mitotic cells (Figure 2B) suggested that TC-A2317 arrested cells at interphase. To characterize the cell cycle arrest in more detail, we determined the levels of cyclin A, cyclin B1 and cyclin D1, which are upregulated in $\mathrm{G} 2$, mitosis and G1, respectively. As expected from the data shown in Figure 2B, the levels of cyclin A and cyclin B1 were significantly reduced in TC-A2317-treated A549 and A427 cells, indicating that the cells were not arrested at G2 or mitosis (Figure 4C). Instead, the upregulation of cyclin D, suggesting a G1 arrest, was observed in A549, not in A427 cells (Figure 4C). However, the levels of cyclins were not dramatically changed in NCI-H1299 cells probably because they are rapidly dividing. Instead, to elucidate the mechanism by which TC-A2317 induces cell cycle arrest, we monitored the levels of p21, a cyclin-dependent kinase inhibitor, and its upstream transcription factor p53. Both p21 and p53 were highly upregulated in TC-A2317-treated A549 cells (Figure 4D). In A427 cells, only p53, not p21, was upregulated. By contrast, although NCI-H1299 cells are p53-null, p21 was upregulated after TC-A2317 treatment. Overall, it suggests that A549 and NCI-H1299 cells underwent p21-dependent cell cycle arrest, but A427 cells underwent p53-depenent apoptosis. To further verify that A549 and NCI-H1299 cells expressing high levels of p21 were senescent, we performed senescence-associated $\beta$-galactosidase (SA- $\beta$-gal) staining. SA- $\beta$-gal activity increased in TC-A2317-treated A549 and NCI-H1299 cells in a time-dependent manner, indicating that TCA2317 induces the irreversible G1 arrest known as senescence (Figure 4E and Supplementary Figure S3B). As expected in Figure 4D, A427 cells did not undergo senescence (Figure 4E and Supplementary Figure S3B). It indicates that $\mathrm{p} 21$ upregulation is required for TCA2317-induced senescence. The vehicle does not affect apoptosis, autophagy and senescence (Supplementary Figure S3A and S3B). In conclusion, major types of cell fate are autophagy and senescence in A549, apoptosis and autophagy in A427, and apoptosis, autophagy and senescence in NCI-H1299 cells, respectively. Overall, these data show that TC-A2317-induced chromosomal instability triggered apoptosis, autophagy or senescence although a type of cell death was dependent on cell type.

\section{TC-A2317-treated cells overcome paclitaxel- induced mitotic arrest}

Next, we used mitosis-arrested cells to investigate the regulatory mechanism by which TC-A2317 affects abnormal mitotic progression. For this purpose, we induced mitotic arrest with paclitaxel, a microtubule stabilizer that interferes with normal microtubule dynamics and ultimately prevents attachment of mitotic spindles to kinetochores. The level of $\mathrm{H} 3-\mathrm{pS} 10$ increased dramatically in paclitaxel-treated cells, but decreased in a time-dependent manner upon TC-A2317 treatment (Figure 5A and Supplementary Figure S4A). This finding indicates that the effects of TC-A2317 allow cells to overcome paclitaxel-induced mitotic arrest. Live-cell imaging revealed that most paclitaxel-treated cells persisted in mitotic arrest, and a subset underwent cell death (Figure 5B). By contrast, cells treated with paclitaxel plus TC-A2317 exited from mitotic arrest and then formed multinucleated cells (Figure 5B). To confirm the formation of multinucleated cells, nuclear morphology was visualized. Post-treatment of TC-A2317 in paclitaxelinduced arrested cells induced the multinucleation (Figure 5C and 5D). Similarly, co-treatment of paclitaxel and MLN-8054 induces multinucleation [20]. These observations demonstrate that TC-A2317-treated cells underwent mitotic slippage, and suggest that TC-A2317 perturbs cellular mechanisms involved in blocking mitotic progression even in the presence of improper mitotic spindles and interferes with maintenance of chromosomal stability.

\section{TC-A2317-treated cells fail to activate the SAC}

To determine how TC-A2317 treatment allows cells to escape mitotic arrest, we performed immunofluorescence staining to monitor the localizations of mitotic kinases, including Aurora A, Aurora B, and BubR1, all of which regulate the SAC. Aurora A was 


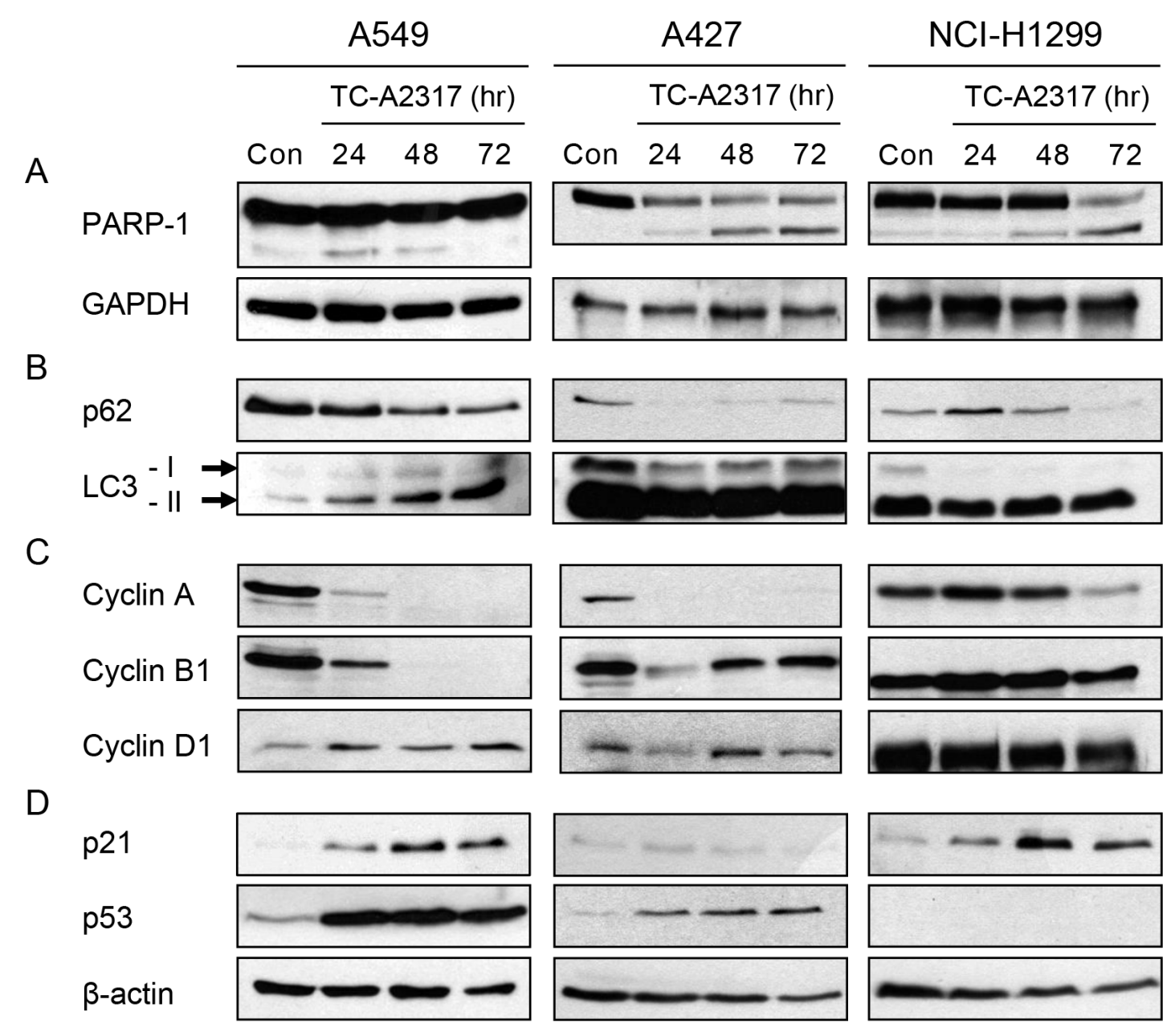

$\mathrm{E}$

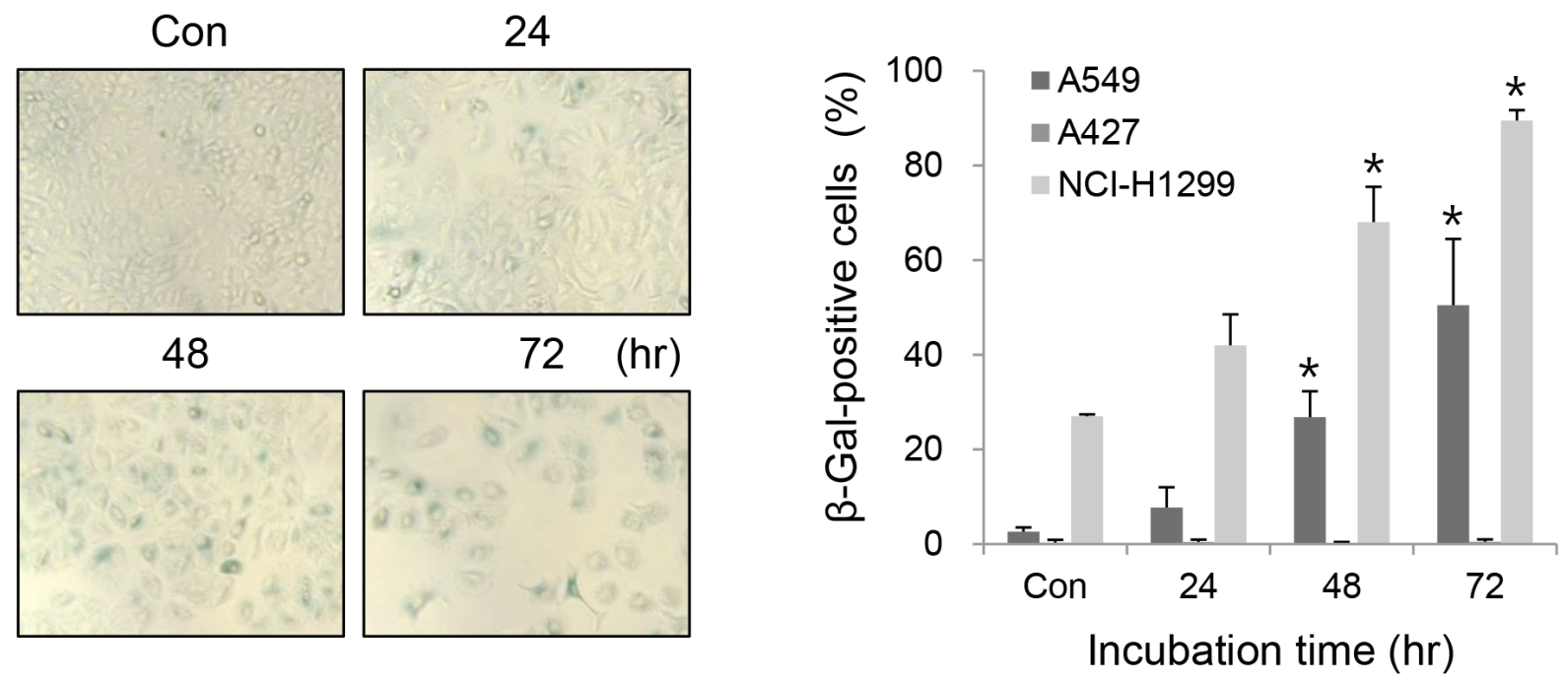

Figure 4: TC-A2317 induces apoptosis, autophagy or senescence. A-E. A549, A427 and NCI-H1299 cells were treated with 1 $\mu \mathrm{M}$ TC-A2317 for the indicated times. Con (Control) means cells treated with vehicle (DMSO) for $72 \mathrm{hr}$. (A-D) Expression level of each protein was evaluated by Western blotting. (E) Senescence-associated $\beta$-galactosidase (SA- $\beta$-Gal) assay was performed and then SA- $\beta$-galpositive cells out of total 250 cells were detected by staining. All values from three independent experiments are represented as means \pm standard deviation $(\mathrm{n}=3)$. Asterisks $(*)$ represent statistically significant differences $(P<0.05$, Student's $t$-test). 
localized to the centrosome, as determined by staining for pericentrin. In control cells, Aurora A and pericentrin were merged in prometaphase. The two proteins were also co-localized in cells treated with paclitaxel, TC-A2317, or paclitaxel plus TC-A2317 (Figure 6A and Supplementary

Figure S5A). In all cells, Aurora B was localized to

A

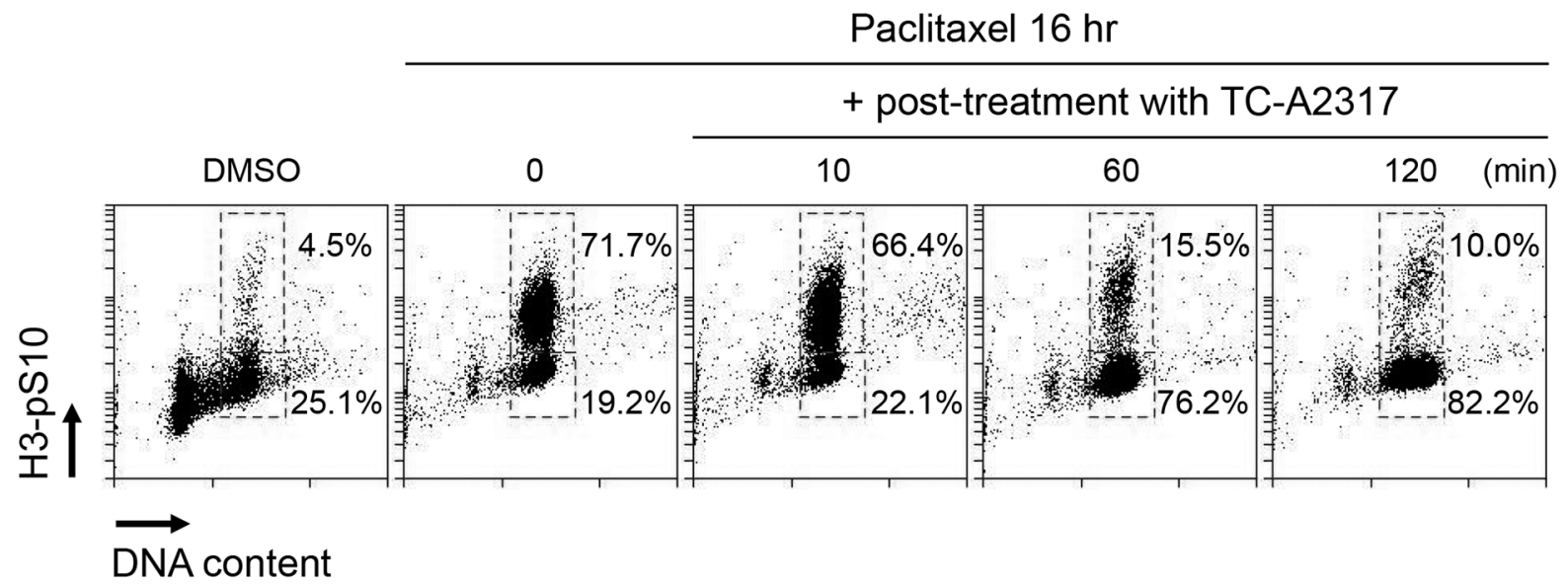

B
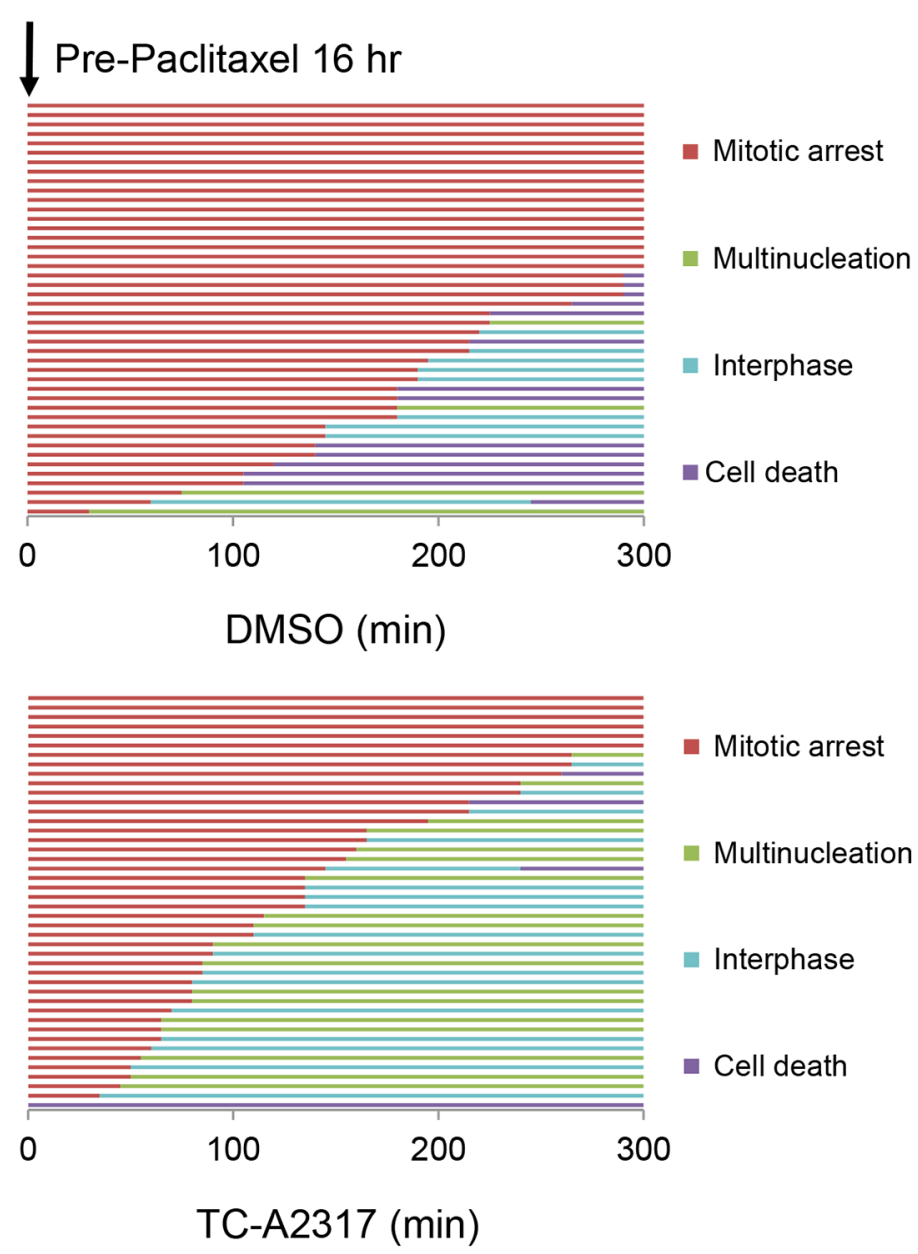

Figure 5: TC-A2317 promotes the exit from mitotic arrest. A549 cells were pre-treated with $50 \mathrm{nM}$ paclitaxel for $16 \mathrm{hr}$, and then treated with $0.5 \mu \mathrm{M}$ TC-A2317 for the indicated times. A. DNA content and H3-pS10 level were determined by flow cytometry. B. H2B-RFPtransduced A549 cells treated with paclitaxel were monitored by time-lapse fluorescence microscopy immediately after addition of DMSO or TC-A2317 for $5 \mathrm{hr}$. Cells undergoing mitotic arrest, multinucleation, interphase, and cell death were counted $(\mathrm{n}=44)$. (Continued) 
C

DMSO

Paclitaxel

+ TC-A2317 2hr

Paclitaxel

+ TC-A2317 5hr

D

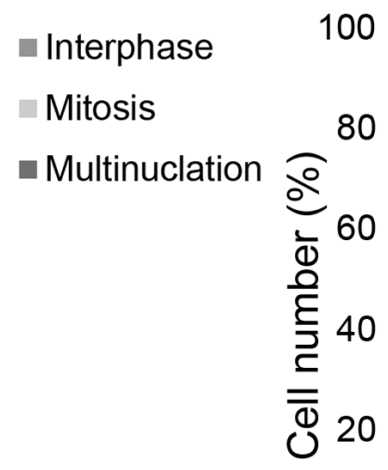

\section{Chromosome $\alpha$-Tubulin Merge}

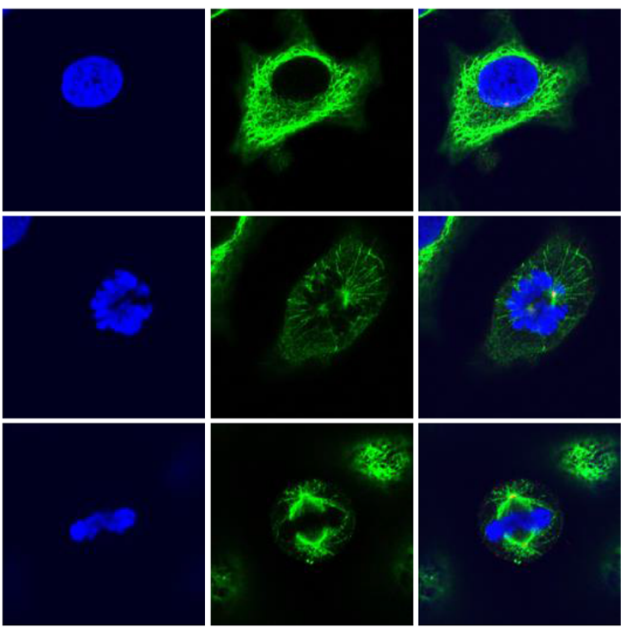

Mitosisarrested
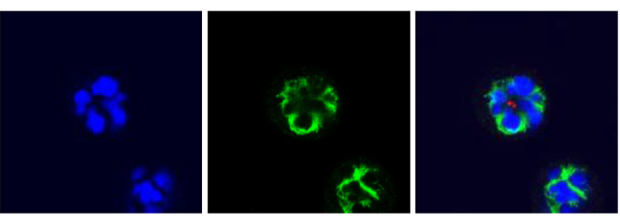

Multinucleated
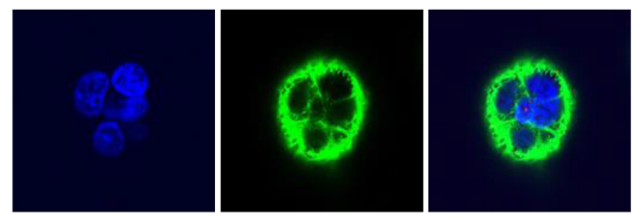

Multinucleated
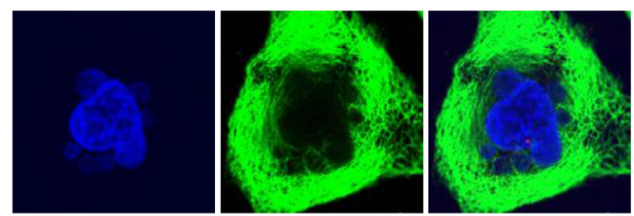

0

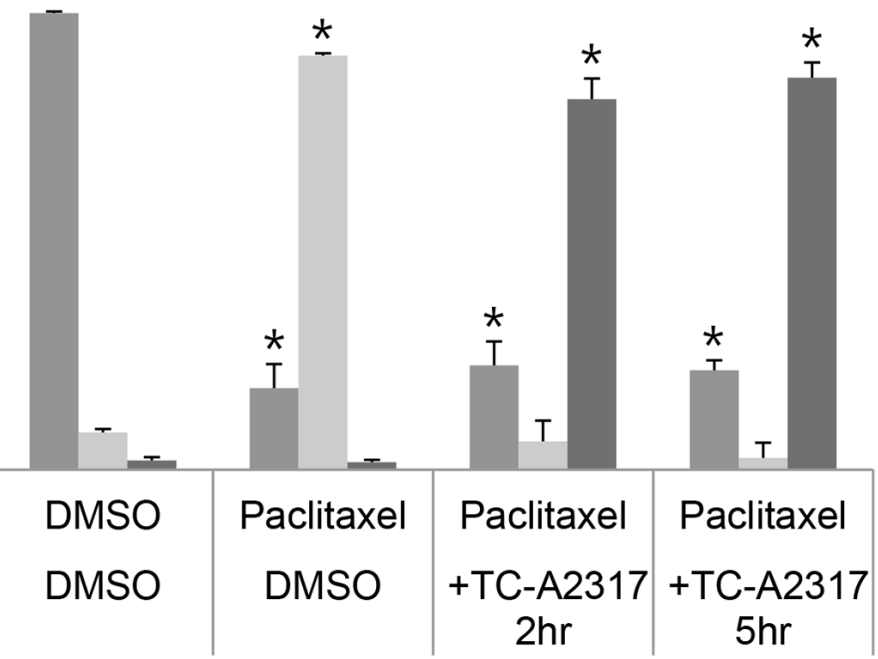

Figure 5: (Continued) TC-A2317 promotes the exit from mitotic arrest. C. The nucleus of the cells and the cell boundary were visualized by staining with Hoechst and $\alpha$-tubulin, respectively. D. Multinucleated cells were counted. All values from three independent experiments are represented as means \pm standard deviation $(\mathrm{n}=3)$. Asterisks $\left.{ }^{*}\right)$ represent statistically significant differences $(P<0.05$, Student's $t$-test). 
A
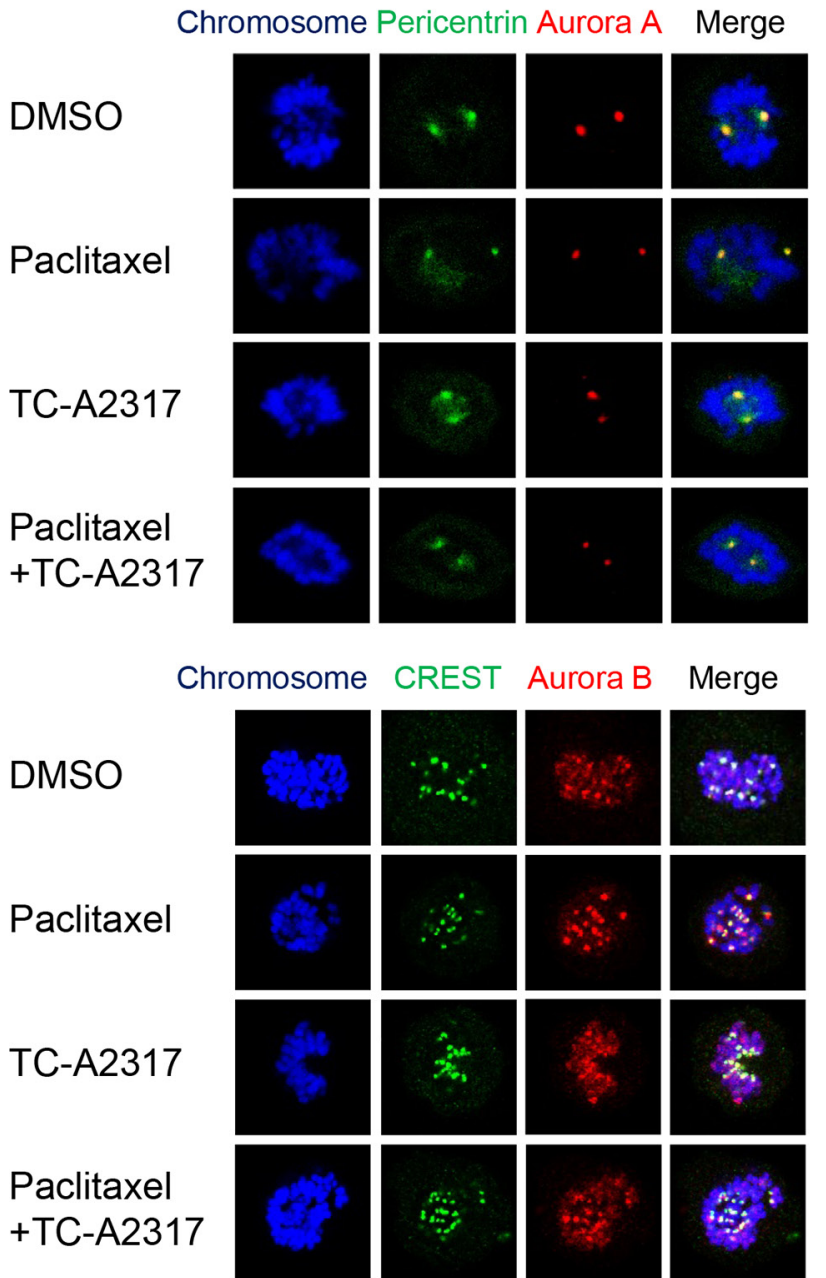

Aurora B
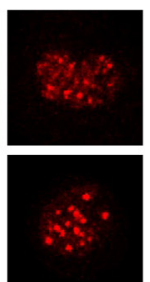

Merge
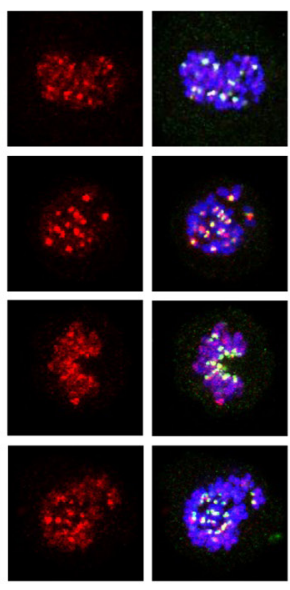

Chromosome CREST
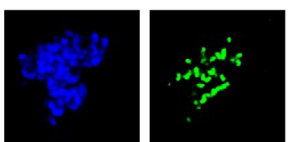

BubR1
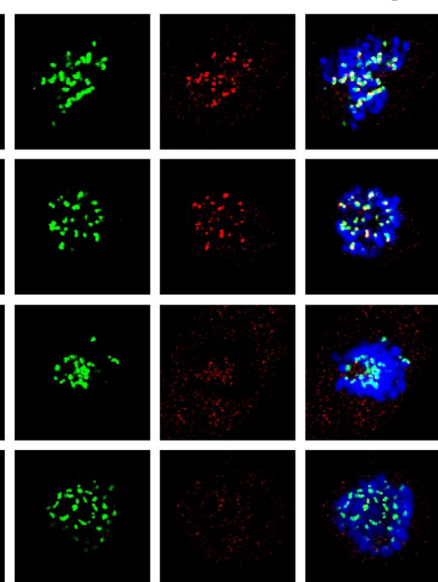

Paclitaxel +TC-A2317
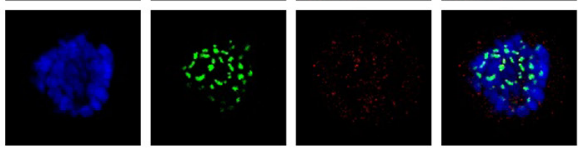

B

Paclitaxel -++++

TC-A2317 - $\quad-1060120(\min )$

p-Aurora A

Aurora A

p-Aurora B

Aurora B

p-PLK1

PLK1

$\beta$-actin
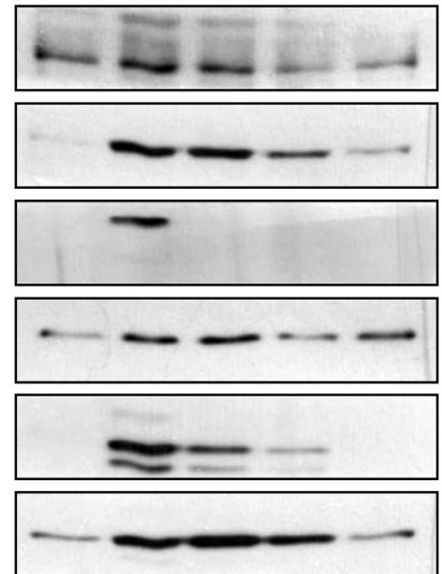

\section{H3-pS10}
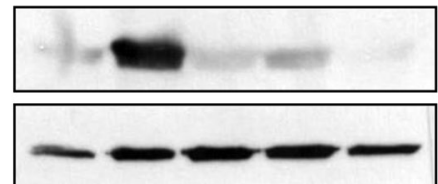

C

Paclitaxel

TC-A2317

$-\quad-1060120 \quad(\min )$

Cyclin B1

Cyclin A

GAPDH
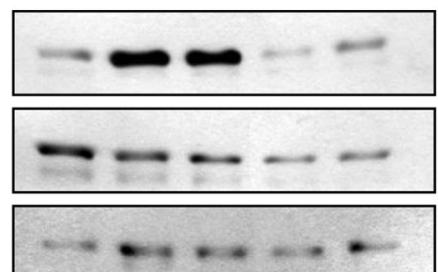

Figure 6: TC-A2317 inactivates paclitaxel-induced SAC. A. A549 cells were treated with $50 \mathrm{nM}$ paclitaxel for $16 \mathrm{hr}$, and then treated with $0.5 \mu \mathrm{M}$ TC-A2317 for $30 \mathrm{~min}$ in the presence of $20 \mu \mathrm{M}$ MG132. Localizations of Aurora A, Aurora B, and BubR1 were determined by staining with the indicated antibodies. B-C. A549 cells were treated with $50 \mathrm{nM}$ paclitaxel for $16 \mathrm{hr}$, and then treated with $0.5 \mu \mathrm{M}$ TC-A2317 for the indicated times. The level of each protein was determined by Western blotting.

kinetochores, as determined by staining with CREST, an anti-centromere autoantibody from sera of patients with CREST syndrome (limited scleroderma) (Figure 6A and Supplementary Figure S5A). BubR1 was localized to kinetochores in prometaphase of control cells and paclitaxel-treated cells (Figure 6A), but not in those of 
cells treated with TC-A2317 or paclitaxel plus TCA2317 (Figure 6A and Supplementary Figure S5A). This was consistent with a previous finding that alisertib reduces recruitment of Bub1 and BubR1 to the kinetochore in nocodazole-treated cells [21]. Together, these data demonstrate that TC-A2317 prevents full activation of SAC. As described in Figure $3 \mathrm{~B}$, the distance between two centrosomes is closer in TC-A2317-treated cells than control cells (Figure 6A and Supplementary Figure S5A) during mitosis, indicating that TC-A2317 treatment results in a defect in centrosome separation. In addition to determining the localization of SAC regulators, we monitored SAC activation by assessing the phosphorylation of each of the proteins involved (Figure 6B and Supplementary Figure S4B). Although paclitaxel increased the level of p-Aurora A, p-Aurora B, and p-PLK1, TC-A2317 decreased the levels of the corresponding phosphoproteins even in the presence of paclitaxel. Thus, TC-A2317 overrides the SAC induced by anti-mitotic agents. To confirm whether cells exited from paclitaxel-induced mitotic arrest, the levels of H3pS10, cyclin B1 and cyclin A were examined. The high level of H3-pS10 and cyclin B1 induced by paclitaxel treatment dramatically decreased upon TC-A2317 treatment (Figure 6B and 6C). By contrast, the level of cyclin A was not changed (Figure 6C), suggesting that the enriched population with H3-pS10-negative 4N DNA was not $\mathrm{G} 2$ cells (Figure 5A). It indicates that the cells exited from mitosis reach the next phase of cell cycle.
Overall, the data suggest that TC-A2317-treated cells lose the ability to ensure proper regulation of chromosomal stability.

\section{Aurora kinase $\mathrm{A}$ is a potential target for cancer therapy}

Aurora A is widely overexpressed in many cancers [8], suggesting that inhibition of the Aurora kinase A is a potential target for cancer therapy. We downloaded the AURKA mRNA levels from TCGA dataset and performed Kaplan-Meier analysis. Kaplan-Meier curves demonstrated that lung cancer patients with high level of AURKA had significantly poorer survival (Figure 7). Thus, Aurora A expression is suggested as a strong predictive value for survival of lung cancer patients.

\section{DISCUSSION}

In this study, we showed that the Aurora kinase A inhibitor TC-A2317 induces abnormal centrosome formation and aberrant mitotic spindles. Even in the presence of mitotic malfunction, TC-A2317-treated cells undergo mitotic slippage. The resultant chromosome mis-segregation leads to inhibition of lung cancer cell proliferation via induction of apoptosis, autophagy, or senescence. In addition, TC-A2317 sensitizes cells to paclitaxel-induced mitotic catastrophe such as multinucleation via an inactivation of SAC.

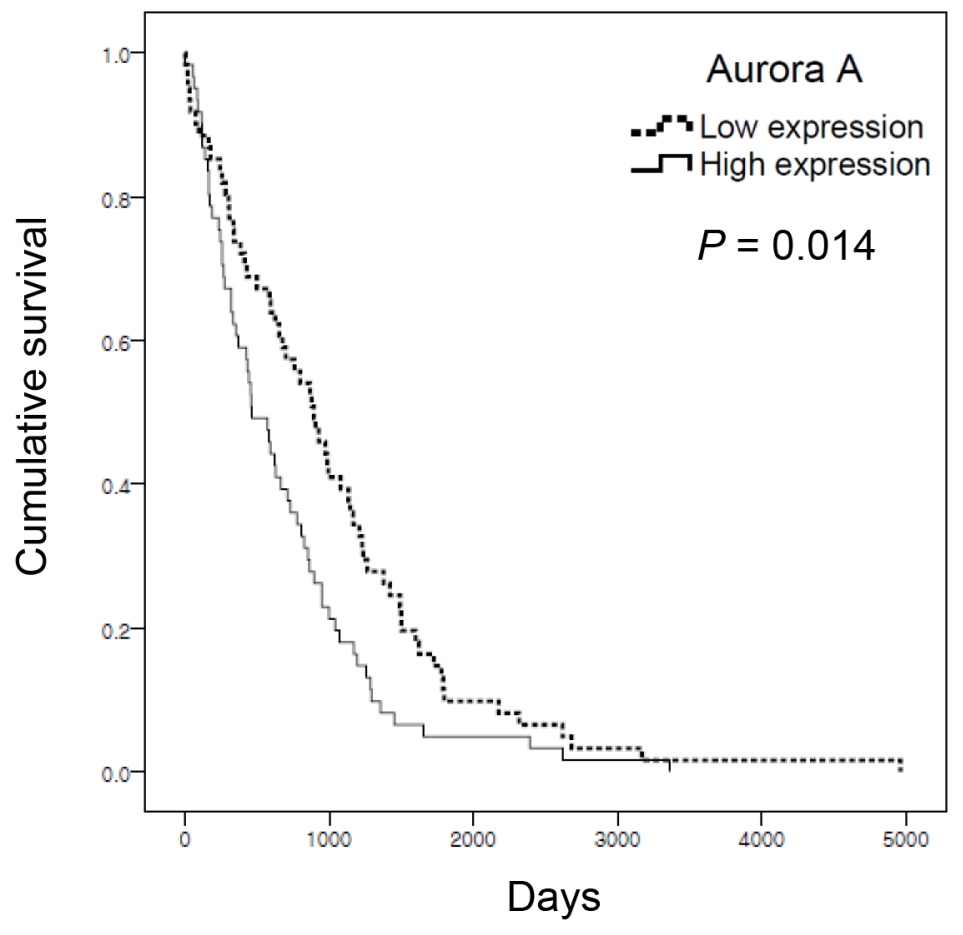

Figure 7: Aurora A expression is associated with low survival of lung adenocarcinoma cancer patients. The mRNA expression data set was obtained from TCGA. Kaplan-Meier survival analysis was performed on 122 dead patients. Aurora A expression was defined as high (above median) or low (below median). $P$-values were based on the log-rank test. 
Inhibition of Aurora kinase A activity by different inhibitors leads to similar phenotypes. ENMD-2076 inhibits proliferation of breast, colon and ovarian cancer, and multiple myeloma in vivo and in vitro. EMND2076-treated cells showed polyploidy and apoptotic cells [22, 23]. MK-5108 (VX-689) inhibits proliferation of breast, colon, and non-small cell lung cancer, leukemia, nasopharyngeal carcinoma, uterine leiomyosarcoma, and ovarian cancer stem cells in vivo and in vitro. The duration of G2 is prolonged by MK-5108 treatment, as also observed in cells treated with siRNA targeting Aurora A [24]. MK-5108 treatment also prolongs mitosis $[25,26]$ and increases the proportion of $\mathrm{H} 3-\mathrm{pS} 10$ positive mitotic cells $[25,27-30]$. MK-5108-treated cells undergo apoptosis $[28,30]$. MLN-8054 inhibits proliferation of colon, prostate, and thyroid cancer, melanoma and neuroblastoma in vivo and in vitro. MLN8054 treatment results in prolonged mitosis [31], abnormal formation of centrosomes and mitotic spindles [31], aneuploidy including multinucleation, micronucleation, and polyploidy [21, 31-36], apoptosis [21, 32, 33, 35], and senescence [37]. The most extensively studied Aurora kinase A inhibitor is an MLN-8237 (alisertib) [38]. Alisertib inhibits proliferation of bladder, breast, cervical, colorectal, esophageal, gastric, lung, pancreatic, and thyroid cancer as well as glioblastoma, leukemia, lymphoma, multiple myeloma, osteosarcoma, tongue squamous cell carcinoma, and uterine leiomyosarcoma. In addition, alisertib treatment induces delayed mitotic entry [39], prolonged mitotic duration [26, 39], defects in mitotic spindle formation [39-42] and cytokinesis [43, 44], multi-centrosomes [39], polyploidy [26, 39, 40, 43-52], DNA damage [36], apoptosis [19, 44-49, 52-57], autophagy [46, 47, 53-55], and senescence [19, 36, 40, $52,56]$.

The novel Aurora kinase A inhibitor TC-A2317 also causes defects in the mitotic spindle, abnormal centrosome, prolonged mitotic duration, aneuploidy, apoptosis, autophagy, and senescence. In comparison with previous studies, distinctive findings of this study include the observations of mitosis portion and instability of centrosomes and microtubules. MK-5108-treated cells are $\mathrm{H} 3-\mathrm{pS} 10-$ positive $[25,27-30]$, indicating that cells are arrested at mitosis. However, as observed in our study, MLN-8237-treated cells contain low levels of H3-pS10 in vitro [43]. TC-A2317 treatment for 48 and $72 \mathrm{hr}$ significantly decreased it, indicating that the cells were not ultimately arrested at mitosis (Figure 2B). Xenograft tumors isolated from mice orally treated with alisertib contain the highest level of $\mathrm{H} 3-\mathrm{pS} 10$ at $8-12$ $\mathrm{hr}$, but lower levels thereafter [50]. These observations suggest that Aurora kinase A inhibitors initially prolong mitotic progression and arrest cells in mitosis, but that the accumulated chromosomal instability eventually overrides the SAC, resulting in permanent cell cycle arrest (i.e., senescence) with polyploidy or apoptosis.
Next, the chromosomal instability induced by Aurora kinase A inhibition might be due to defects in centrosome and mitotic spindle formation. The second difference between the results of this study and previous reports involves centrosome number. Brief treatment $(5 \mathrm{hr})$ with MLN-8054 leads to the formation of monocentrosome and multipolar spindles. By contrast, longer treatment $(>24$ $\mathrm{hr}$ ) results in centrosome amplification [31]. Treatment with alisertib for $24 \mathrm{hr}$ induces formation of monopolar spindles in glioblastoma stem cells, but multipolar spindles in differentiated glioma cells [40]. By contrast, in our study, TC-A2317 induced a defect in centrosome separation during mitosis (Figure 3B, Figure 6A and Supplementary Figure S5A), and finally a formation of monocentrosome in interphase (Figure 3A). Third, brief treatment $(4 \mathrm{hr})$ with a high dose of alisertib treatment dramatically increases the proportion of cells with no mitotic spindles [39]. Alisertib treatment also causes loss of inter-microtubule bridges by disrupting the TACC $3 / \mathrm{ch}$ TOG/clathrin complex and prevents cold-stable K-fiber attachment to the kinetochore $[42,58]$. Our study also demonstrates that TC-A2317-treated cells have unstable mitotic spindles. However, acute treatment with alisertib (15 min) results in microtubule hyperstabilization and subsequent spindle pole fragmentation [41]. Thus, these differences in centrosomes and mitotic spindles might be dependent on both the identity of the specific drug used and the incubation time. Moreover, although TC-A2317mediated SAC inactivation leads to mitotic slippage, mitotic duration is not shortened; instead, the prolonged mitotic duration might be due to abnormal centrosome separation and microtuble destabilization.

The significant reduction in cell proliferation resulting from treatment with Aurora kinase A inhibitor can be explained by induction of apoptosis, autophagic cell death, or senescence, all of which can be regulated by p53. In fact, Aurora A regulates the level and activity of p53 by phosphorylating residue Ser315, thereby destabilizing the protein [59], as well as Ser215, thereby diminishing DNA-binding activity [60]. Consistent with this finding, treatment with Aurora kinase A inhibitors such as MK5108 , MK-8054, or alisertib induces upregulation of p53 [21, 26, 37, 55, 61]. However, when p53 is deleted in breast cancer, alisertib induces senescence rather than apoptosis [56]. In HCT116 p53\% cells, MK-5108 treatment prolongs mitosis and generates more polyploidy after mitotic slippage [26]. In addition, MK-8745, a specific Aurora kinase A inhibitor, also causes apoptosis in HCT116 p53 $3^{+/+}$cells, but induces polyploidy in HCT116 p5 $3^{-/}$cells [62]. Overall, these findings demonstrate that p53 is required for induction of apoptosis by Aurora kinase A inhibition; in the absence of p53, the same treatment aggravates polyploidy and induces senescence. Consistent with the previous findings, our study also demonstrated that p53-null NCI-H1299 cells dramatically underwent senescence than p53-wild type A549 and A427 cells. 
However, NCI-H1299 cells also underwent significant apoptosis even in the absence of p53, suggesting that other apoptosis-inducing factors are involved. The senescence induced by Aurora kinase A inhibition might be mediated by cyclin-dependent kinase inhibitor p21. In this study, except for A427 cells, A549 and NCI-H1299 cells treated with TC-A2317 upregulated p21, as previously observed in MLN-8054-treated HCT116 cells [37] and MLN8237-treated HT29 and Caco-2 cells [54]. However, although p53 was upregulated in TC-A2317-treated A427 cells, p21 was not changed, supporting that TC-A2317 did not induce senescence in A427 cells. The different phenomenon between A549 and A427 cells could be addressed by K-ras mutation. While A549 cells harbor K-ras ${ }^{\mathrm{G} 12 \mathrm{~S}}$, A427 cells contain K-ras ${ }^{\mathrm{G} 12 \mathrm{D}}$ which suppresses senescence [63]. Overall, the p53 or other factor can induce apoptosis, and p21 can induce senescence in TCA2317-treated cells.

The SAC is activated when mitotic spindles are not correctly attached to kinetochores. SAC activation at unattached kinetochores halts the onset of anaphase to prevent separation of sister chromatids until the chromosomes are properly attached [1]. Several antimitotic agents that interfere with microtubule dynamics, including paclitaxel, vincristine, and vinblastine, activate SAC, ultimately inducing mitotic arrest and mitotic catastrophe. Therefore, anti-mitotic agents have been utilized as conventional anti-cancer drugs. Because pharmacological inhibition of Aurora kinase A overrides SAC-mediated mitotic arrest and aggravates chromosomal instability, the combination of anti-mitotic agents and Aurora kinase A inhibitor enhances chemosensitivity. Aurora kinase A inhibition by MK-5108 and alisertib increases the anti-tumor activity of docetaxel, paclitaxel, and vincristine [27, 48, 51, 64-66], whereas Aurora A overexpression increases resistance to taxol [67]. Overall, targeting the mitotic functions of Aurora A using pharmacological inhibitors increases the anti-cancer effect of anti-mitotic agents.

\section{MATERIALS AND METHODS}

\section{Cell culture}

A549 (p53-wild type, p16-null) and A427 (p53-wild type, p16-null) non-small cell lung cancer cells were obtained from the American Type Culture Collection (ATCC, Lot No. 58314291 and 58696830, respectively) and maintained in Dulbecco's modified Eagle's medium (DMEM, Welgene Inc.). NCI-H1299 (p53-null, p16-deficient) cells were obtained from the Korean Cell Line Bank (KCLB) and maintained in Roswell Park Memorial Institute (RPMI) 1640. All media were supplemented with $10 \%$ fetal bovine serum (FBS), $100 \mathrm{U} / \mathrm{ml}$ penicillin G sodium, $100 \mu \mathrm{g} / \mathrm{ml}$ streptomycin sulfate, and $0.25 \mu \mathrm{g} / \mathrm{ml}$ amphotericin B. Cells were incubated at $37^{\circ} \mathrm{C}$ in $5 \% \mathrm{CO}_{2}$ incubator.

\section{Drug treatment}

Cells were treated with 0.5 or $1 \mu \mathrm{M}$ TC-A2317 (Tocris, 4066), $0.5 \mu \mathrm{M}$ alisertib (Selleckchem, S1133) or $50 \mathrm{nM}$ paclitaxel (EMD Millipore, 580555) for indicated times. All drugs are dissoved in DMSO as a vehicle. The final concentration of vehicle in culture medium was $0.1 \%$.

\section{Cell viability assay}

Cells $\left(7.5 \times 10^{3}\right.$ cells per well) were plated in a 96well plate and then treated with TC-A2317 for $24 \mathrm{hr}$. MTT (3-(4,5-dimethylthiazol-2-yl)-2,5-diphenyltetrazolium bromide) was added to each well, and the plate was incubated at $37^{\circ} \mathrm{C}$ for $4 \mathrm{hr}$ to allow formation of MTT formazan crystals. After the culture medium was removed, the formazan crystals was dissolved using dimethyl sulfoxide. The absorbance was measured with a test wavelength of $570 \mathrm{~nm}$ and a reference wavelength of $650 \mathrm{~nm}[68]$.

\section{Clonogenic assay}

Cells $\left(5 \times 10^{2}\right.$ cells per $60 \mathrm{~mm}$ dish $)$ were plated and then incubated for 14 days. After removal of the medium, cells were rinsed with phosphate-buffered saline (PBS), fixed in acetic acid:methanol (1:7, vol/vol) at room temperature for $5 \mathrm{~min}$, and then stained with staining solution ( $0.5 \%$ crystal violet in $25 \%$ methanol). Colonies were counted on triplicate dishes, and independent experiments were repeatedly done [68].

\section{Cell cycle analysis}

Cells were suspended in PBS and then 100\% ethanol was added to be the final concentration of $70 \%$ ethanol while gently vortexing. The fixed cells were permeabilized with $0.25 \%$ Triton X-100 in PBS on ice for $15 \mathrm{~min}$. The cells were incubated with anti-H3-pS10 (Histone H3 phosphorylation at S10, Upstate, 06-570) antibody for 2 $\mathrm{hr}$, and then incubated with FITC-conjugated goat antirabbit IgG (Jackson ImmunoResearch Laboratories Inc., 111-095-144) at room temperature in the dark for $1 \mathrm{hr}$. Cells were incubated with DNase-free RNase A at $37^{\circ} \mathrm{C}$ for $30 \mathrm{~min}$ and then with propidium iodide (PI) at $37^{\circ} \mathrm{C}$ in the dark for another $30 \mathrm{~min}$. The cell cycle phase and H3pS10-positive cells were determined by flow cytometry and analyzed using C6 software. The percentage of each cycle phase was analyzed using Modfit software [68].

\section{Immunofluorescence staining}

Cells grown on coverslips were fixed with $3 \%$ paraformaldehyde solution at room temperature for 10 min and then permeabilized with $0.5 \%$ Triton X-100 at room temperature for $5 \mathrm{~min}$. The cells were incubated 
with antibody against Aurora A (BD Biosciences, 610938), Aurora B (Santa Cruz, sc-25426), BubR1 (BD Biosciences, 612503), Pericentrin (Abcam, 28144) or CREST (ImmunoVision, HCT-0100) at $37{ }^{\circ} \mathrm{C}$ for 20 min and then incubated with corresponding secondary antibody at $37{ }^{\circ} \mathrm{C}$ for $20 \mathrm{~min}$. For the staining with $\alpha$-tubulin (Abcam, 18251) and pericentrin antibodies, the cells were fixed with cold methanol at $-20{ }^{\circ} \mathrm{C}$ for $20 \mathrm{~min}$ and then rehydrated in PBS three times. The cells were post-fixed with paraformaldehyde and permeabilized as described above. The nuclei were counterstained with Hoechst 33342. After a final wash with PBS, coverslips were mounted with antifade solution containing paraphenylenediamine and glycerol in PBS. The staining was determined using laser-scanning confocal microsope (LSM700, Carl Zeiss). Images are acquired using ZEN software (Carl Zeiss) [68].

\section{Microtubule depolymerization assay}

Cells grown on coverslips were cultured in the presence of $2 \mathrm{mM}$ thymidine for 19 hours and then released to grow for $10 \mathrm{hr}$. Cells were then treated with 2 $\mathrm{mM}$ thymidine for another 15 hours, causing cells to arrest at the G1/S boundary. The thymidine was washed off with PBS, and the arrested cells were allowed to progress to mitosis for $10 \mathrm{hr}$. To block the anaphase transition, $20 \mu \mathrm{M}$ MG132 was added for $1 \mathrm{hr}$. Subsequently, the cells were incubated with TC-A2317 in cold media on ice for $5 \mathrm{~min}$ in the absence of MG132. Cells were stained with $\alpha$-tubulin antibody, and metaphase cells with depolymerized mitotic spindles were counted [41].

\section{Time-lapse microscopy}

TSiN-H2B-RFP lentiviral construct was kindly gifted by Dr. P. J. Galardy (Mayo Clinic). Lentivirus was prepared by transfection of HEK293T cells with TSiNH2B-RFP lentiviral plasmid, psPAX2 packaging plasmid, and pMD2.G envelope plasmid. A549 cells were infected with lentivirus encoding $\mathrm{H} 2 \mathrm{~B}-\mathrm{RFP}$ in the presence of 8 $\mu \mathrm{g} / \mathrm{ml}$ polybrene. Time-lapse imaging was acquired using a Cell Observer (Cell Observer Living Cells, Carl Zeiss) equipped with a camera and Axiovision (Carl Zeiss). Frames were recorded every $5 \mathrm{~min}$. Cell morphology was visualized on a phase-contrast microscope, and RFP was detected by fluorescence [68].

\section{Western blotting}

Cells were lysed using NETN buffer (100 mM $\mathrm{NaCl}, 1 \mathrm{mM}$ EDTA, $20 \mathrm{mM}$ Tris-HCl pH 8.0, 0.5\% Nonidet P-40, $50 \mathrm{mM} \beta$-glycerophosphate, $10 \mathrm{mM} \mathrm{NaF}$ and $1 \mathrm{mM} \mathrm{Na}_{3} \mathrm{VO}_{4}$ ) with protease inhibitor (Millipore, 535140 ) on ice for $10 \mathrm{~min}$. After centrifugation at $12,000 \times \mathrm{g}$ for $5 \mathrm{~min}$, the supernatant was saved as a crude cell extract. The crude cell extracts were boiled in the Laemmli buffer and then loaded onto a SDSpolyacrylamide gel [68]. The antibodies used for Western blotting are as follows: PARP-1 (Santa Cruz Biotechnology, sc-7150), p62/SQSTM1 (Cell signaling, 5114), LC3 (MBL International, PM036), Cyclin A (Santa Cruz Biotechnology, sc-751), Cyclin B1 (Santa Cruz Biotechnology, sc-752), Cyclin D1 (Santa Cruz Biotechnology, sc-753), p53 (Santa Cruz Biotechnology, sc-126), p21 (EMD Millipore, OP64), Aurora A-pT288 (Cell Signaling, 3079), Aurora A (Cell Signaling, 4718), Aurora A-pT288/Aurora B-pT232/Aurora C-pT198 (Cell Signaling, 2914), Aurora B (Cell Signaling, 3094), PLK1-pT210 (Santa Cruz Biotechnology, sc-135706), PLK1 (Cell Signaling, 4513), H3-pS10 (Upstate, 06570), $\beta$-actin (Cell Signaling, 4970), and GAPDH (Santa Cruz Biotechnology, sc-25778).

\section{Senescence-associated $\beta$-galactosidase staining}

The cells were washed with PBS, then fixed and stained at pH 6.0 using a senescence $\beta$-galactosidases (SA$\beta$-gal) staining kit (Cell Signaling, 9860) according to the manufacturer's instructions [69].

\section{Statistical analysis}

All experiments were done three times. Each value was expressed as means \pm standard deviations. Student's t-test was used for statistical analysis and statistical difference was considered significant when $P<0.05$.

\section{Association analysis of aurora kinase a expression with patient survival}

Expression data were downloaded from The Cancer Genome Atlas (TCGA) (https://tcga-data.nci.nih.gov). AURKA transcript level in lung adenocarcinoma patients was determined by RNA-Seq V2 and processed using the SUBIO platform (version 1.19). For each sample, Aurora A expression was defined as high (above median) or low (below median). The association of transcript level with patient survival was visualized using Kaplan-Meier curves, and significance of differences was assessed by log-rank test using SPSS (version 12.0).

\section{CONFLICTS OF INTEREST}

The authors declare that they have no conflict of interest.

\section{GRANT SUPPORT}

This research was supported by Basic Science Research Program through the National Research Foundation of Korea(NRF) funded by the Ministry of Science, ICT and future Planning(2015R1A2A2A01007438). 


\section{REFERENCES}

1. Lara-Gonzalez P, Westhorpe FG and Taylor SS. The spindle assembly checkpoint. Curr Biol. 2012; 22:R966-980.

2. Hochegger H, Hegarat $\mathrm{N}$ and Pereira-Leal JB. Aurora at the pole and equator: overlapping functions of Aurora kinases in the mitotic spindle. Open Biol. 2013; 3:120185.

3. Carmena M and Earnshaw WC. The cellular geography of aurora kinases. Nat Rev Mol Cell Biol. 2003; 4:842-854.

4. Quartuccio SM and Schindler K. Functions of Aurora kinase $\mathrm{C}$ in meiosis and cancer. Front Cell Dev Biol. 2015; 3:50.

5. Carmena M, Ruchaud S and Earnshaw WC. Making the Auroras glow: regulation of Aurora A and B kinase function by interacting proteins. Curr Opin Cell Biol. 2009; 21:796-805.

6. Nikonova AS, Astsaturov I, Serebriiskii IG, Dunbrack RL, Jr. and Golemis EA. Aurora A kinase (AURKA) in normal and pathological cell division. Cell Mol Life Sci. 2013; 70:661-687.

7. Reboutier D, Benaud C and Prigent C. Aurora A's Functions During Mitotic Exit: The Guess Who Game. Front Oncol. 2015; 5:290.

8. Malumbres $\mathrm{M}$ and Perez de Castro I. Aurora kinase A inhibitors: promising agents in antitumoral therapy. Expert Opin Ther Targets. 2014; 18:1377-1393.

9. Goldenson B and Crispino JD. The aurora kinases in cell cycle and leukemia. Oncogene. 2015; 34:537-545.

10. Karthigeyan D, Prasad SB, Shandilya J, Agrawal S and Kundu TK. Biology of Aurora A kinase: implications in cancer manifestation and therapy. Med Res Rev. 2011; 31:757-793.

11. Stenoien DL, Sen S, Mancini MA and Brinkley BR. Dynamic association of a tumor amplified kinase, Aurora-A, with the centrosome and mitotic spindle. Cell Motil Cytoskeleton. 2003; 55:134-146.

12. Tanaka M, Ueda A, Kanamori H, Ideguchi H, Yang J, Kitajima $\mathrm{S}$ and Ishigatsubo Y. Cell-cycle-dependent regulation of human aurora A transcription is mediated by periodic repression of E4TF1. J Biol Chem. 2002; 277:10719-10726.

13. Zhou H, Kuang J, Zhong L, Kuo WL, Gray JW, Sahin A, Brinkley BR and Sen S. Tumour amplified kinase STK15/ BTAK induces centrosome amplification, aneuploidy and transformation. Nat Genet. 1998; 20:189-193.

14. Wang X, Zhou YX, Qiao W, Tominaga Y, Ouchi M, Ouchi $\mathrm{T}$ and Deng CX. Overexpression of aurora kinase A in mouse mammary epithelium induces genetic instability preceding mammary tumor formation. Oncogene. 2006; 25:7148-7158.

15. Portella G, Passaro C and Chieffi P. Aurora B: a new prognostic marker and therapeutic target in cancer. Curr Med Chem. 2011; 18:482-496.

16. Kollareddy M, Zheleva D, Dzubak P, Brahmkshatriya PS, Lepsik M and Hajduch M. Aurora kinase inhibitors: progress towards the clinic. Invest New Drugs. 2012; 30:2411-2432.
17. Dar AA, Goff LW, Majid S, Berlin J and El-Rifai W. Aurora kinase inhibitors--rising stars in cancer therapeutics? Mol Cancer Ther. 2010; 9:268-278.

18. Ando R, Ikegami H, Sakiyama M, Ooike S, Hayashi M, Fujino Y, Abe D, Nakamura H, Mishina T, Kato H, Iwase Y, Tomozane H and Morioka M. 3-Cyano-6-(5-methyl3-pyrazoloamino) pyridines: selective Aurora A kinase inhibitors. Bioorg Med Chem Lett. 2010; 20:4709-4711.

19. Van Brocklyn JR, Wojton J, Meisen WH, Kellough DA, Ecsedy JA, Kaur B and Lehman NL. Aurora-A inhibition offers a novel therapy effective against intracranial glioblastoma. Cancer Res. 2014; 74:5364-5370.

20. Wysong DR, Chakravarty A, Hoar K and Ecsedy JA. The inhibition of Aurora A abrogates the mitotic delay induced by microtubule perturbing agents. Cell Cycle. 2009; 8:876-888.

21. Kaestner P, Stolz A and Bastians H. Determinants for the efficiency of anticancer drugs targeting either Aurora-A or Aurora-B kinases in human colon carcinoma cells. Mol Cancer Ther. 2009; 8:2046-2056.

22. Diamond JR, Eckhardt SG, Tan AC, Newton TP, Selby HM, Brunkow KL, Kachaeva MI, Varella-Garcia M, Pitts TM, Bray MR, Fletcher GC and Tentler JJ. Predictive biomarkers of sensitivity to the aurora and angiogenic kinase inhibitor ENMD-2076 in preclinical breast cancer models. Clin Cancer Res. 2013; 19:291-303.

23. Wang X, Sinn AL, Pollok K, Sandusky G, Zhang S, Chen L, Liang J, Crean CD, Suvannasankha A, Abonour R, Sidor C, Bray MR and Farag SS. Preclinical activity of a novel multiple tyrosine kinase and aurora kinase inhibitor, ENMD-2076, against multiple myeloma. Br J Haematol. 2010; 150:313-325.

24. de Groot CO, Hsia JE, Anzola JV, Motamedi A, Yoon M, Wong YL, Jenkins D, Lee HJ, Martinez MB, Davis RL, Gahman TC, Desai A and Shiau AK. A Cell Biologist's Field Guide to Aurora Kinase Inhibitors. Front Oncol. 2015; 5:285.

25. Li J, Hong MJ, Chow JP, Man WY, Mak JP, Ma HT and Poon RY. Co-inhibition of polo-like kinase 1 and Aurora kinases promotes mitotic catastrophe. Oncotarget. 2015; 6:9327-9340. doi:10.18632/oncotarget.3313.

26. Marxer M, Ma HT, Man WY and Poon RY. p53 deficiency enhances mitotic arrest and slippage induced by pharmacological inhibition of Aurora kinases. Oncogene. 2014; 33:3550-3560.

27. Shimomura T, Hasako S, Nakatsuru Y, Mita T, Ichikawa K, Kodera T, Sakai T, Nambu T, Miyamoto M, Takahashi I, Miki S, Kawanishi N, Ohkubo M, et al. MK-5108, a highly selective Aurora-A kinase inhibitor, shows antitumor activity alone and in combination with docetaxel. Mol Cancer Ther. 2010; 9:157-166.

28. Chinn DC, Holland WS and Mack PC. Anticancer activity of the Aurora A kinase inhibitor MK-5108 in non-smallcell lung cancer (NSCLC) in vitro as monotherapy and in combination with chemotherapies. J Cancer Res Clin Oncol. 2014; 140:1137-1149. 
29. Shan W, Akinfenwa PY, Savannah KB, Kolomeyevskaya N, Laucirica R, Thomas DG, Odunsi K, Creighton CJ, Lev DC and Anderson ML. A small-molecule inhibitor targeting the mitotic spindle checkpoint impairs the growth of uterine leiomyosarcoma. Clin Cancer Res. 2012; 18:3352-3365.

30. Sparta AM, Bressanin D, Chiarini F, Lonetti A, Cappellini A, Evangelisti C, Evangelisti C, Melchionda F, Pession A, Bertaina A, Locatelli F, McCubrey JA and Martelli AM. Therapeutic targeting of Polo-like kinase-1 and Aurora kinases in T-cell acute lymphoblastic leukemia. Cell Cycle. 2014; 13:2237-2247.

31. Hoar K, Chakravarty A, Rabino C, Wysong D, Bowman D, Roy N and Ecsedy JA. MLN8054, a small-molecule inhibitor of Aurora A, causes spindle pole and chromosome congression defects leading to aneuploidy. Mol Cell Biol. 2007; 27:4513-4525.

32. Dar AA, Belkhiri A, Ecsedy J, Zaika A and El-Rifai W. Aurora kinase A inhibition leads to p73-dependent apoptosis in p53deficient cancer cells. Cancer Res. 2008; 68:8998-9004.

33. Manfredi MG, Ecsedy JA, Meetze KA, Balani SK, Burenkova O, Chen W, Galvin KM, Hoar KM, Huck JJ, LeRoy PJ, Ray ET, Sells TB, Stringer B, et al. Antitumor activity of MLN8054, an orally active small-molecule inhibitor of Aurora A kinase. Proc Natl Acad Sci U S A. 2007; 104:4106-4111.

34. Moretti L, Niermann K, Schleicher S, Giacalone NJ, Varki V, Kim KW, Kopsombut P, Jung DK and Lu B. MLN8054, a small molecule inhibitor of aurora kinase a, sensitizes androgen-resistant prostate cancer to radiation. Int J Radiat Oncol Biol Phys. 2011; 80:1189-1197.

35. Wunderlich A, Fischer M, Schlosshauer T, Ramaswamy A, Greene BH, Brendel C, Doll D, Bartsch D and Hoffmann S. Evaluation of Aurora kinase inhibition as a new therapeutic strategy in anaplastic and poorly differentiated follicular thyroid cancer. Cancer Sci. 2011; 102:762-768.

36. Liu Y, Hawkins OE, Su Y, Vilgelm AE, Sobolik T, Thu YM, Kantrow S, Splittgerber RC, Short S, Amiri KI, Ecsedy JA, Sosman JA, Kelley MC, et al. Targeting aurora kinases limits tumour growth through DNA damage-mediated senescence and blockade of NF-kappaB impairs this druginduced senescence. EMBO Mol Med. 2013; 5:149-166.

37. Huck JJ, Zhang M, McDonald A, Bowman D, Hoar KM, Stringer B, Ecsedy J, Manfredi MG and Hyer ML. MLN8054, an inhibitor of Aurora A kinase, induces senescence in human tumor cells both in vitro and in vivo. Mol Cancer Res. 2010; 8:373-384.

38. Niu H, Manfredi M and Ecsedy JA. Scientific Rationale Supporting the Clinical Development Strategy for the Investigational Aurora A Kinase Inhibitor Alisertib in Cancer. Front Oncol. 2015; 5:189.

39. Asteriti IA, Di Cesare E, De Mattia F, Hilsenstein V, Neumann B, Cundari E, Lavia P and Guarguaglini G. The Aurora-A inhibitor MLN8237 affects multiple mitotic processes and induces dose-dependent mitotic abnormalities and aneuploidy. Oncotarget. 2014; 5:6229-6242. doi: 10.18632/oncotarget.2190.
40. Mannino M, Gomez-Roman N, Hochegger $\mathrm{H}$ and Chalmers AJ. Differential sensitivity of Glioma stem cells to Aurora kinase A inhibitors: implications for stem cell mitosis and centrosome dynamics. Stem Cell Res. 2014; 13:135-143.

41. Asteriti IA, Giubettini M, Lavia $P$ and Guarguaglini G. Aurora-A inactivation causes mitotic spindle pole fragmentation by unbalancing microtubule-generated forces. Mol Cancer. 2011; 10:131.

42. Cheeseman LP, Booth DG, Hood FE, Prior IA and Royle SJ. Aurora A kinase activity is required for localization of TACC $3 /$ ch-TOG/clathrin inter-microtubule bridges. Commun Integr Biol. 2011; 4:409-412.

43. Baldini E, Tuccilli C, Prinzi N, Sorrenti S, Antonelli A, Fallahi P, Mian C, Barollo S, Catania A, Morrone S, Tartaglia F, Mascagni D, Coccaro C, et al. Selective inhibitors of aurora kinases inhibit proliferation, reduce cell viability and impair cell cycle progression in papillary thyroid carcinoma cells. J Biol Regul Homeost Agents. 2015; 29:793-803.

44. Zullo KM, Guo Y, Cooke L, Jirau-Serrano X, Mangone M, Scotto L, Amengual JE, Mao Y, Nandakumar R, Cremers S, Duong J, Mahadevan D and O'Connor OA. Aurora A Kinase Inhibition Selectively Synergizes with Histone Deacetylase Inhibitor through Cytokinesis Failure in T-cell Lymphoma. Clin Cancer Res. 2015; 21:4097-4109.

45. Baldini E, Tuccilli C, Prinzi N, Sorrenti S, Antonelli A, Gnessi L, Morrone S, Moretti C, Bononi M, ArlotBonnemains Y, D'Armiento $\mathrm{M}$ and Ulisse S. Effects of selective inhibitors of Aurora kinases on anaplastic thyroid carcinoma cell lines. Endocr Relat Cancer. 2014; 21:797-811.

46. Niu NK, Wang ZL, Pan ST, Ding HQ, Au GH, He ZX, Zhou ZW, Xiao G, Yang YX, Zhang X, Yang T, Chen XW, Qiu JX, et al. Pro-apoptotic and pro-autophagic effects of the Aurora kinase A inhibitor alisertib (MLN8237) on human osteosarcoma U-2 OS and MG-63 cells through the activation of mitochondria-mediated pathway and inhibition of $338 \mathrm{MAPK} / \mathrm{PI} 3 \mathrm{~K} / \mathrm{Akt} / \mathrm{mTOR}$ signaling pathway. Drug Des Devel Ther. 2015; 9:1555-1584.

47. Yuan CX, Zhou ZW, Yang YX, He ZX, Zhang X, Wang D, Yang T, Wang NJ, Zhao RJ and Zhou SF. Inhibition of mitotic Aurora kinase A by alisertib induces apoptosis and autophagy of human gastric cancer AGS and NCI-N78 cells. Drug Des Devel Ther. 2015; 9:487-508.

48. Zhou N, Singh K, Mir MC, Parker Y, Lindner D, Dreicer R, Ecsedy JA, Zhang Z, Teh BT, Almasan A and Hansel DE. The investigational Aurora kinase A inhibitor MLN8237 induces defects in cell viability and cell-cycle progression in malignant bladder cancer cells in vitro and in vivo. Clin Cancer Res. 2013; 19:1717-1728.

49. Qi W, Spier C, Liu X, Agarwal A, Cooke LS, Persky DO, Chen D, Miller TP and Mahadevan D. Alisertib (MLN8237) an investigational agent suppresses Aurora $\mathrm{A}$ and $\mathrm{B}$ activity, inhibits proliferation, promotes endoreduplication and induces apoptosis in T-NHL cell lines 
supporting its importance in PTCL treatment. Leuk Res. 2013; 37:434-439.

50. Manfredi MG, Ecsedy JA, Chakravarty A, Silverman L, Zhang M, Hoar KM, Stroud SG, Chen W, Shinde V, Huck JJ, Wysong DR, Janowick DA, Hyer ML, et al. Characterization of Alisertib (MLN8237), an investigational small-molecule inhibitor of aurora A kinase using novel in vivo pharmacodynamic assays. Clin Cancer Res. 2011; 17:7614-7624.

51. Qi W, Cooke LS, Liu X, Rimsza L, Roe DJ, Manziolli A, Persky DO, Miller TP and Mahadevan D. Aurora inhibitor MLN8237 in combination with docetaxel enhances apoptosis and anti-tumor activity in mantle cell lymphoma. Biochem Pharmacol. 2011; 81:881-890.

52. Gorgun G, Calabrese E, Hideshima T, Ecsedy J, Perrone G, Mani M, Ikeda H, Bianchi G, Hu Y, Cirstea D, Santo L, Tai YT, Nahar S, et al. A novel Aurora-A kinase inhibitor MLN8237 induces cytotoxicity and cell-cycle arrest in multiple myeloma. Blood. 2010; 115:5202-5213.

53. Shu LP, Zhou ZW, Zi D, He ZX and Zhou SF. A SILACbased proteomics elicits the molecular interactome of alisertib (MLN8237) in human erythroleukemia K562 cells. Am J Transl Res. 2015; 7:2442-2461.

54. Ren BJ, Zhou ZW, Zhu DJ, Ju YL, Wu JH, Ouyang MZ, Chen XW and Zhou SF. Alisertib Induces Cell Cycle Arrest, Apoptosis, Autophagy and Suppresses EMT in HT29 and Caco-2 Cells. Int J Mol Sci. 2016; 17.

55. Li JP, Yang YX, Liu QL, Pan ST, He ZX, Zhang X, Yang T, Chen XW, Wang D, Qiu JX and Zhou SF. The investigational Aurora kinase A inhibitor alisertib (MLN8237) induces cell cycle G2/M arrest, apoptosis, and autophagy via p38 MAPK and Akt/mTOR signaling pathways in human breast cancer cells. Drug Des Devel Ther. 2015; 9:1627-1652.

56. Tentler JJ, Ionkina AA, Tan AC, Newton TP, Pitts TM, Glogowska MJ, Kabos P, Sartorius CA, Sullivan KD, Espinosa JM, Eckhardt SG and Diamond JR. p53 Family Members Regulate Phenotypic Response to Aurora Kinase A Inhibition in Triple-Negative Breast Cancer. Mol Cancer Ther. 2015; 14:1117-1129.

57. Brewer Savannah KJ, Demicco EG, Lusby K, Ghadimi MP, Belousov R, Young E, Zhang Y, Huang KL, Lazar AJ, Hunt KK, Pollock RE, Creighton CJ, Anderson ML, et al. Dual targeting of mTOR and aurora-A kinase for the treatment of uterine Leiomyosarcoma. Clin Cancer Res. 2012; 18:4633-4645.

58. Lioutas A and Vernos I. Aurora A kinase and its substrate TACC 3 are required for central spindle assembly. EMBO Rep. 2013; 14:829-836.

59. Katayama H, Sasai K, Kawai H, Yuan ZM, Bondaruk J, Suzuki F, Fujii S, Arlinghaus RB, Czerniak BA and Sen
S. Phosphorylation by aurora kinase A induces Mdm2mediated destabilization and inhibition of p53. Nat Genet. 2004; 36:55-62.

60. Liu Q, Kaneko S, Yang L, Feldman RI, Nicosia SV, Chen $\mathrm{J}$ and Cheng JQ. Aurora-A abrogation of p53 DNA binding and transactivation activity by phosphorylation of serine 215. J Biol Chem. 2004; 279:52175-52182.

61. Davis SL, Robertson KM, Pitts TM, Tentler JJ, BradshawPierce EL, Klauck PJ, Bagby SM, Hyatt SL, Selby HM, Spreafico A, Ecsedy JA, Arcaroli JJ, Messersmith WA, et al. Combined inhibition of MEK and Aurora A kinase in KRAS/PIK3CA double-mutant colorectal cancer models. Front Pharmacol. 2015; 6:120.

62. Nair JS, Ho AL and Schwartz GK. The induction of polyploidy or apoptosis by the Aurora A kinase inhibitor MK8745 is p53-dependent. Cell Cycle. 2012; 11:807-817.

63. Lee KE and Bar-Sagi D. Oncogenic KRas suppresses inflammation-associated senescence of pancreatic ductal cells. Cancer Cell. 2010; 18:448-458.

64. Huck JJ, Zhang M, Mettetal J, Chakravarty A, Venkatakrishnan K, Zhou X, Kleinfield R, Hyer ML, Kannan K, Shinde V, Dorner A, Manfredi MG, Shyu $\mathrm{WC}$, et al. Translational exposure-efficacy modeling to optimize the dose and schedule of taxanes combined with the investigational Aurora A kinase inhibitor MLN8237 (alisertib). Mol Cancer Ther. 2014; 13:2170-2183.

65. Mahadevan D, Morales C, Cooke LS, Manziello A, Mount DW, Persky DO, Fisher RI, Miller TP and Qi W. Alisertib added to rituximab and vincristine is synthetic lethal and potentially curative in mice with aggressive DLBCL co-overexpressing MYC and BCL2. PLoS One. 2014; 9:e95184.

66. Sehdev V, Katsha A, Ecsedy J, Zaika A, Belkhiri A and El-Rifai W. The combination of alisertib, an investigational Aurora kinase A inhibitor, and docetaxel promotes cell death and reduces tumor growth in preclinical cell models of upper gastrointestinal adenocarcinomas. Cancer. 2013; 119:904-914.

67. Anand S, Penrhyn-Lowe S and Venkitaraman AR. AURORA-A amplification overrides the mitotic spindle assembly checkpoint, inducing resistance to Taxol. Cancer Cell. 2003; 3:51-62.

68. Choi M, Kim W, Cheon MG, Lee CW and Kim JE. Pololike kinase 1 inhibitor BI2536 causes mitotic catastrophe following activation of the spindle assembly checkpoint in non-small cell lung cancer cells. Cancer Lett. 2015; 357:591-601.

69. Kim W, Kim R, Park G, Park JW and Kim JE. Deficiency of H3K79 histone methyltransferase Dot1-like protein (DOT1L) inhibits cell proliferation. J Biol Chem. 2012; 287:5588-5599. 